Genth: Ueber Korund, seine Umwandlungen ete. 49

Ueber Korund, seine Umwandlungen, und die ihn begleitenden Mineralien;

\author{
ron \\ F. A. Genth ${ }^{3}$.
}

Vor etwa drei Jahren kamen mir eigenthümliche, aus Hindostan stammende, mit Korund eusammen vorkommende Krystalle zu Gesicht, deren Form die des Korunds war, während die damit angestellte chemisehe Untersuchung die Zusammensetzung eines Spinelle ergab. Diese interesasnte Thatsacho führte zum Studium anderer Umwandlungsproducte des Korunds, desen Resultat SohlussPolgerungen ergab, relohe niobt nar für Chemiker und Mineralogen, sondern namentlich für Grologen von ganz besonderer Wiohtigkeit sein dürften. Entfernt von vollständigen wissenschaftlichen Bibliotheken oder grösseren Sammlangen, und nur mit den nothdürftigaten Hülfsmitteln aungestattet, kann ich mir kaum eriauben, mich auf weitare Discussionen einzulasmen, und bin gonöthigt, mioh lediglich auf meine eignen Beobrohtungen zu besohrïnken.

Doch ehe ich mich dem eigentlichen Gegenstande meiner Untersuchung zuwende, möge es mir vergönnt sein, einen kurzen Ueberblick über dio geologischen Vorhältnisse zu geben, unter denen Korund in Masse suftritt.

In den zum Laurentischen System gehörenden Schichten ist der Korund fast unbekannt, nar wenige isolirte Kryatalle weissen, rothen und blauen Korunds sind in dem darin auftretenden körnigen Kalk beobachtet worden, so namentllich in Begleitang von rothem Spinell, Ohondrodit, Hormblende, Graphit and vielen andern Mineralien

1) Für dieses Journal naoh dar vor der Ameriown Pbilosophical Bociety am 9. September 1878 golesenen Abhandlung wm Verf. bearbeitot.

D. Rod.

Joaro. f. prakt Chomie [2] Bd. 0. 
50 Genth: Ueber Korund, seine Umwandlungen,

zu Warwick und Amity in New-York und Newton, Vernon and Franklin in Newajersey; ebenso in Canada.

Die mächtigsten bis jetzt beobachteten Korundlager finden sich in der Chromit-haltigen Serpentin- oder vielmehr Chrysolith-Formation, und in den diese einschliessendeu Felsarten. Zahllose Localitäten sind innerhalb der letzten Jahre in einer Längenerstreckung von beinahe tausend Meilen (englisch) in den Vereinigten Staaten aufgefunden worden, von Massachusetts bis nach Alabama.

Woher die enormen Quantitäten von Thonerde gekrommen, die als Korund abgelagert sind, dessen spätere Umwandlung zur Bildung vieler unserer am weitesten verbreiteten Felsarten beitrug, wird stets eine böchst interessante Frage sein.

Die wichtigste Ablagerung von Korund in den östlichen Staaten wurde durch C. 'T. Jacks on ${ }^{1}$ ) zu Chester, Mass., entdeckt, und spater durch C. U. Shepard ${ }^{2}$ ) and

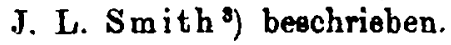

Sie besteht entweder aus feinkörnigem Korund mit feinschuppigem Chlorit oder aus einem eigenthümlichen Gemenge von körnigem und kryetallisirtem Korund mit (titanhaltigem) Magnetit, und einem chloritisehen Mineral.

Das ganze Lager durchsetzt im Herzen der Grünen Berge mit einer durchschnittlichen Mäohtigkeit von vier Fuss zwei Berge auf eine Distanz von etwa vier Meilen, und liegt in Talkschiefer und Serpentin zwischen Gneiss und Glimmerschiefer. Der Gneiss enthält keinen Korund, die kalkigen Schichten dagegen enthalten durch die ganze Masse vertheilt, Sinirgel, Korund und Magneteisen. Ein mehrere Zoll mächtiger Gang von feinkörnigem Oligoklas mit eingemengten Stückchen ron Korund durchsetzt die ohloritische Felsart.

Der Korund selbst tritt gewöhnlich in kleinen bräunlichen Krystallen auf oder in sehr feinen Körnchen; die

1) C. T. Jackson, Sill. Journ. [2] 38, 88.

2) C. U. S he pard, Sill. Journ. [2] 40, 112-128; 42, 421; 46, 256.

7) J. L. Smith, Sill. Journ. [2] $42,89$. 
Varietät Sapphir findet sich mitunter in sechsseitigen Doppelpyramiden. Blassrother Margarit, Diaspor und Korundophilit umbüllen häufig den Smirgel sowohl als den Korund. Andere Begleiter sind Turmalin, Cyanit, Chloritoia, Ilmenit, Rutil u. s. w. Mit dem Oligoklas findet sich ein dunkelgrüner Biotit.

Jacks on war der Ansicht, worin ihm Shepard beistimmte, dass der Smirgel (emery) von Chester die Zasammensetzung des Hercynits, $\mathrm{FeO}, \mathrm{Al}_{2} \mathrm{O}_{3}$, besitze, was J. L. Smith bereits widerlegt hat.

Ich will hier noch einige Korundlooslitäten in den östlichen Staaten erwähnen, die möglicher Weise nicht zu der chromithaltigen Serpentinformation gehören.

J. H. Adams ${ }^{\text {) }}$ beobachtete ihn in geringer Menge und selten auf ursprünglicher Lagerstätte zu Pelham, Mass., in platten Massen eines braunschwarzen Glimmers (Biotit, Shepard \%), welche Knollen von Korundophilit (Vermiculit, Shepard) mit eingeschlossenem woissem und sapphirblauem Korund enthalten.

Zu Litchfield, Conn., findet er sich in Kugeln von Cyanit stets in Begleitung von Talk und Diaspor (She pard) and vollständig von Fibrolit eingehüllt zu Norwich, Conn., in kleinen Krystallen von sapphirblauer Farbe (Shepard).

In Pennsylvania tritt er mohr oder weniger massenhaft in den Grafsohaften Delaware und Chester zwisohen Serpentin und granitischen und gneissartigen Felsarten in einer Ausdehnung von etwa fünf Meilen auf.

Bei Mineral Hill und Black Horse bei Medis in der Grafschaft Delaware findet sich ein körniges, granitisches Gestein, welches aus einem weissen oder gelblich-weissen triklinischen Feldspath, der auf den Spaltungsflächen sehr deutliche Streifung zeigt, aber bereits grossen Theils in Kaolin umgewandelt ist, besteht, keinen Quarz zu enthalten scheint, dagegen hie und da Blättchon von braunschwarzem Biotit, und durch die ganze Masse vertheilt

1) J. H. Adams, Sill. Journ. [2] 49, 272.

2) C. U. Shopard, Sill. Journ. [3] 4, 179-180. 
Krystalle von Korund, theilweise mit einem Ueberzug eines glimmerartigen Minerals (Damourit) theilweise mehr oder weniger vollständig in Fibrolit umgewandelt. Viele lose Krystalle finden sich in der Erde.

Bei Unionville in der Grafschaft Chester hatte man seit langer Zeit nioht allein Krystalle, sondern auch lose Blöcke von massigem Korund gefunden; die Lagerstätte, von welchem diese Bruchstücke kamen, wurde vor etwas länger als einem Jahre entdeckt. Zur Zeit meines Besuchs vor etwa sechs Monaten war durch Tagebau eine fast solide Masse von Korund blossgelegt, die eine Länge von ohngefähr dreissig Fuss hatte, und zwischen fünf und zehn Fuss dick war, bei einer Tiefe von fünfzehn Fuss.

Der Korund ist grobkörnig, zeigt nur selten Spaltungsflächen; von bräunlich-grauer Farbe und lässt, wie die in der Erde gefundenen Krystalle, eine mehr oder weniger weit fortgeschrittene Umwandlung in andre Mineralien wahrnehmen. Folgende sind an dieser Localität beobachtet worden: Diaspor, Gibbsit (Seal ${ }^{1}$ ) Damourit, Margarit, Natron-Margarit, Euphyllit, Zoisit, Turmalin, Chlorit, Lesleyit und Pattersonit.

Etwa eine Meile entfernt von Unionville am Weg nach Kennett Square findet sich Korund in körnigen Albit eingeschlossen, begleitet von Euphyllit und Turmalin, und in Gesellschaft von schwarzem Spinell, Chlorit, Talk, Actinolit u. s. w.

Von Maryland ist mir kein Korund za Gesicht gekommen, und von Virginia nur ein Stück, das auf das Vorhandensein eines Korund-Lagers schliessen lässt, nämlich ein Bruchstück eines Gerölles aus der Nachbarschaft von Staunton in der Grafschaft Augusta, hauptsächlich aus Chloritoid bestehend, in Begleitung von Damourit. Eine qualitative Analyse zeigte im Chloritoid eine Beimengung sehr feiner Theilchen von Korund.

Vón grossem wissenschaftlichem Interesse sind die Verhältnisse, unter denen Korund, in Nordcarolina, Süd

1) T. F. Seal, Sill. Journ. [2] 11, 267. 
carolina, Georgia und Alabama auftritt. Das östlichste Vorkommen, welches zur nämlichen chromithaltigen Chrysolit-Formation za gehören scheint, findet sich in der Nachbarschaft von Friendship in der Grafschaft Guilford, und kommt in Begleitung reicher titanhaltiger MagnetitLager vor. Der Korund ist ein echter' Smirgel, ron grauweisser and röthlicher Farbe, feinkörnig und innig mit Magnetit gemengt. Accessorische Mineralien sind Chlorit, gewöhnlich in ein woisses glimmerartiges Mineral umgewandelt, Ilmenit und höchst geringe Mengen Chromit.

Die Analyse zweier Muster gab:

$$
\begin{aligned}
& \text { Korund }=52,24-44,86 \\
& \text { Magnetit }=42,77-46,29 \\
& \text { Silicate }=4,99-8,85 \\
& \hline
\end{aligned}
$$

Das ganze Lager liegt im Granit und obgleich in der Nähe weder Chrysolit noch Serpentin vorkommt, so macht die Gegenwart des Chromits nnd die Aehnlichkeit des Chlorits mit dem aus Serpentin, es dennoch höchst wahrscheinlich, dass das ganze Vorkommen hierher gehört.

Die grösste Ausdehnung erreicht der Korund im westlichen und südwestlichen Nordcarolina, und eine oft unterbrochene Reihe von Korund-Lagern erstreckt sich auf eine Entfernung von mehr als 250 Meilen von den Grafschaften Madison und Jancey in Nordcarolina durch Georgia bis nach der Grafschaft Tallapoosa in Alabama.

Die erste grosse Masse von Korund wurde im Jahre 1847 am French Broad River, drei Meilen unterhalb Marshall in der Grafsehaft Madison gefunden. Er war von dunkelbrauner Farbe und von Chlorit und Margarit begleitet. Das Lager, von dem dieser über 100 Pfund schwere Block und einige kleinere Blöcke hergekommen, ist bis jetzt nicht aufgefunden worden; doch lassen die damit vorkommenden Mineralien keinen $Z_{w}$ eifel uibrig, dass sie aus der grossen Chrysolit-Formation stammen, die in lins enförmigen Lagern zwischen Granit, Gneiss and Hornblend eschiefer u. s. w. auftreten. Ich glaube der Erste ge- 
54 Genth: Ueber Korund, seine Umwandlungen,

wesen zu sein, welcher darauf aufmerksam machte, dass die chrom- und nickelhaltigen Serpentine und Talkschiefer der Zersetzung von Chrysolit-Fels ihre Entstehung verdanken 1); eine Ansicht, die sich seitdem allgemeine Geltung verschafft hat, vor Kurzem durch die ausgezeichneten Untersuchungen der Serpentine und serpentinartiger Felsarten durch R. v. Drasche ${ }^{2}$ ).

C. U. Shepard ${ }^{3}$ ) hat vor Kurzem in einem ausgedehnteren Artikel die Vorkommnisse in Nordcarolina und Georgia behandelt. Er sucht darin zu zeigen, dass es nicht Chrysolit, sondern Villarsit sei, der die Hauptmasse der Formation bildet. Ich bat desshalb Thomas M. Chatard, ein Stück von der Culsagee-Grube in der Nachbarschaft von Franklin, Grafschaft Macon zu untersuchen und gebe zum Vergleich meine alte Analyse (l. c.) einer Varietät von Webster, Grafschaft Jackson, N. C.:

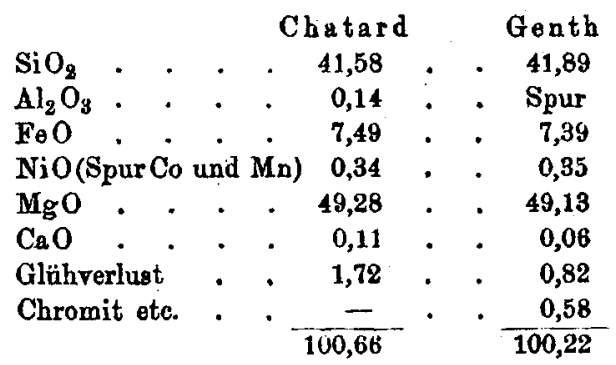

Villarsit ist nur eine Zwischenstufe in der Zersetzung des Chrysolits in Serpentin. Eine Felsart, welche aus einem serpentinähnlichen Mineral und einem triklinischen Feldspath besteht, tritt unter ähnlichen Verhältnissen zu Cul-

1) F. A. Genth, Sill. Journ. [2] 83, 202.

2) R. v. Drasche, in G. Tschermak's Mineralogischen Mittheilungen, 1871. 1. (R. v. Drasche erwähnt Serpentin von Easton Pa., als aus Chrysolit entstanden. Diess ist sicher ein Irrthum, da der an dieser Localität vorkommende Serpentin aus Pyroxen entstanden ist. Das untersuchte Stück hatte wahrscheinlich eine falsche Bezeichnung. .

3) C. U. Shepard, Sill. Journ. [3] 4, 109-114 und 175-180. 
lakenee oder anf der. Buck Creek-Grube in der Grafschaft Clay auf.

Die Zusammensetzung des serpentinähnlichen Minerals (jedooh mit nicht ganz reinem Material angestellt) gab:

$$
\begin{aligned}
& \mathrm{SiO}_{2} \text { (durch Differenz) }=35,19 \\
& \mathrm{Al}_{2} \mathrm{O}_{3} \text {. . . . }=0,64 \\
& \mathrm{~F}_{\mathbf{8}} \mathrm{O} \text {. . . } \approx \mathbf{8 , 7 0} \\
& \mathrm{MgO} \text {. . . . }=40,99 \\
& \text { Glühverlust . . } \frac{=18,48}{100,00}
\end{aligned}
$$

Die Culsagee-Grube ist die am besten aufgeschlossene. Das Ausgehende erstreckt sich uber dreissig Acker. Die suftretenden Felserten sind: Chrysolitfels, eine Sohicht Glimmerschiefer, eine Sobicht einer chloritischen Felsart.

Das Luger ist durohsetzt durch Schnüre von Chalcedon und Andesit, sowie feinkörnigen Oligoklas, ähnlich dem von Chester, Mass.

Namentlich im Chlorit kommt der Korund vor, in Körnern, Krystallen und schmalen Gängen, die sich inanchmal zu mehreren Fuss Mächtigkeit erweitern, ausserdem ein schwarzgrüner Spinell in dünnen Schnüren, mitunter mit schwarzem Turmalin gemengt. Der Chlorit ist häufg in andere Mineralien umgewandelt bis zu einer Tiefe von 50 bis 60 Fuss, und der darin enthaltene Korund zerfallt leicht zu Fragmenten. Der Glimmerachiefer sowohl wie der Andesit enthalten Krystalle und Fragmente von Korund. - Andere begleitende Mineralien sind Actinolit, Asbest, Talk, Rutil u. s. w.

Etwa 20 Meilen südwestlich von Culsagee ist ein anderes sehr interessantes Vorkommen auf der sogenannten Cullskenee-Grube bei Bnck Creek in der Grafschaft Clay beobachtet. Der Chrysolitfels nimmt einen Raum von etwa 300 Acker ein, und enthält die gewöhnlichen accessorischen Mineralien, wie Actinolit, Pikrolit u. 8. w. Etwo in der Mitte des Chrysolit-Lagers tritt eine eigenthümliche Felsart auf, die dem bei Hof in Bayern vorkommenden Eklogit täuschend ähnlich ist, und aus grasgrünem, griunlichgrauem oder schwärzlichem Smaragdit, einem weissen 
56 Genth: Ueber Korand, seine Umwandlungen,

triklinischen Feldspath und hochrothem Rubin besteht, häufig Cyanit und Chromit enthïlt und mitunter von Schnüren von Zoisit durchrogen ist. - Der Korand der Cullakenee-Grube ist gewöhnlieh von graulich-weisser oder hell aschgrauer Farbe, selten rait dunkel sapphirblauen Flecken, doch kommen auch auspezeichnete rosenrothe und dunkelrothe Varietäten vor. Begleitende Mineralien sind namentlich Andesit, Zoisit, Margarit, Hornhlende und, dann and wann, Chlorit, Spinell, Turmalin und ein eigenthümliches unter dem Namen Willcoxit besohriebenes Mineral.

Viele sndere Isocalitäten in Nordcarolina zu Pentland's, Shooting Creek, Hogback u. s. w., sowie in den Grafschaften Raban und Towns in Georgia und Tallapoosa in Alabama bieten ganz uhnliche Verhältnisse wie Culsagee und Cullakenee.

Eigenthümlich ist das Vorkommen des Korands zu Gainesville in der Grafschaft Hall in Georgia. Die damit auftretende Felsart scheint eine Varietät Steatit zu sein, ausserdem hell grünlich-weisse, dem Talkschiefer sohr ähnlich sehende Schiefer, die aber nach der von Dr. G. A. Koenig angestellten Analyse echte Chloritschiefer sind. Sie enthalten:

$$
\begin{aligned}
& \mathrm{SiO}_{2} \text {. . . }=30,98 \\
& \mathrm{Al}_{2} \mathrm{O}_{3} \text {. . }=20,80 \\
& \mathrm{Fe}_{2} \mathrm{O}_{3} \cdot \text {. }=4,00 \\
& \mathrm{FeO} \text {. . . }=4,11 \\
& \mathrm{MgO} \text {. . . }=27,79 \\
& \text { Glïhverluste } \quad=\frac{12,62}{99,75} \text {. }
\end{aligned}
$$

Der Korund findet sich als Kern in unregelmässigen nierenförmigen Massen feinblättrigen Margarits oder mit einem tigenthümlichen erdigen, zwischen isabell- und fleischfarbigem Mineral, das mit Schnürchen von massivem oder feinschuppigem grünlichem Margarit durchzogen ist. Dunkelgrïner blättriger Chlorit, Actinolit, Asbest and Turmalin finden sich an der nämlichen Localität.

Diesem Auftreten des Korunds in Verbindung mit 
der amerikanischen chromithaltigen Chrysolit- oder Serpentin-Formation ist ganz analog das im Ural von Gastar Rose') beschriebene.

Zu Mramorsk an der Westseite eines Marmorbruchs, ist ein Bruch eines lauchgrünen Serpentins und ein anderor von grünlich-8chwarzem Chloritschiofer gemengt mit feinkömigem Smirgel. Der Chloritschiefer onthält kleine Gänge oder Ausscheidangen, die mit einem rosenrothen röthlich-brannen Mineral ausgefullt sind, ausserdem mit blittrigem Chlorit, einem weissen glimmerartigen Minersl und gelblich-grsuem körnigem Zoisit. Einige von den Gangen enthalten Diaspor und Chloritoid. Der Marmorbruch za Kassoibrod liegt zwischen Chloritschiefer zut seiner westlichen Seite und Granit auf der östlichen. Im Chloritschiefer fond sich ein Krystall von blauem Korund in Form einer sechsseitigen Säule mit Endfläche mit weissem sternartigen Schimmer.

In der Regel ist nur wenig Korand im Chloritschiefer vorhanden, gewöhnlich in Begleitung von 'Turmalin, Chlorit u. s. w.

Nach den wichtigen Mittheilungen, dio J. L. Smith ') über das Vorkommen des Smirgels, Korunds und der sie begleitenden Mineralien in Kleinssien und tem griechi* schen Archipel machte, finden sich dieselben in Marmor oder körnigem Kalk; der Kalk liegt anf Alimmerschiefer, Gneiss oder Granit. Die den Korund begleitenden Mineralien sind: Diaspor, Gibbsit, Zinkspinell, Pholerit, Ephesit, Margerit, Glimmer (? Muscovit) Chloritoid, schwarzer Tarmalin, Chlorit, Magnetit, Limonit, Rutil, Ilmenit and Titaneisen.

Diess sind so ziemlich slle mit den amorikanischen chromithaltigen Chrysoliten und 'Serpentinen vorkommende Species, und eg ist höchst wahrecheinlich, was auch J. L. Smith ${ }^{3}$ ) neuerdings constatirt, dass die Bmirgel-Lager in Kleinasien und Griechenland von analogem Alter sind.

') G. Rose, Roice naoh dem Ural I, 161. 248. 256.

7) J. L. Smith, Bill. Journ. [2] 10, 355 ff. and 11, 58 ff.

ग) J. L. $8 \mathrm{mith}$, Sill. Journ. [\$] 6, 180-186. 
58 Genth: Ueber Korund, seine Umwandlungen,

Noch sind einige Vorkommnisse von Korund und von, aus der Zersetzung von Korund, entstandenen Mineralien zu erwähnen, welche in andern Formationen auftreten, vor allen das in den sogenannten Taconischen Schiefern von F. Emmons ${ }^{2}$.

Der meiste bis jetzt darin beobachtete Korund erscheint in losen Massen vou geringer Grösse, gewöhnlich von grauer, blauer oder röthlich-blauer Farbe, manchmal in Krystallen nit deutlicher Spaltbarkeit, gewöhnlich aber derb. Ein sehr charakteristischer Begleiter ist Rutil in Krystallen oder körnigen Massen, ausserdem Cyanit, Damourit, Pyrophyllit, Lazulit und körniger Quarz. Fundorte sind Crowder's Mountain und Clubb's Mountain in der Grafschaft Gaston und eine neuerdings entdeckte Localität in der Grafschaft Rutherford in Nordearolina. Es ist sehr wahrscheinlich, dass die Lager von Pyrophyllit in deu Grafschaften Orange, Chatham, Moore und Montgomery in Nordcarolina, sowie die von Graves Mountain in der Grafsehaft Lincoln in Georgia den Korund führenden Schichten in der Grafschaft Rutherford u. Gaston analog sind.

Höchst interessant und wahrscheinlich analog dem Vorkommen des Korunds in Blöcken von Cyanit in Connecticut, ist das ind Cyanit aus dem Gneiss bei Swannanoa Gap in der Grafschaft Buncombe und das in der Grafschaft Wilkes in Nordcarolins.

Das Vorkommen von Korund in Lqurens Distrikt in Südcarolina scheint nach den vorliegenden Stücken dem Glimmerschiefer anzugehören und wahrscheinlich analog zu sein dem zu Culsagee im Glimmerschiefer vorkommenden Korund. Nur Krystalle sind mir zu Gesicht gekommen und diese besteben gewöhnlich aus rauhen Doppelpyramiden von einem bis drei Zoll Läuge und einem viertel Zoll bis zu einem Zoll Dicke. Alle Krystalle sind melhr oder weniger ungewandelt, manche haben nur einen Ueberzug eines glimmerartigen Minerals, wübrend

1) Ebenezer $\mathbf{E m m o n a , ~ G e o l . ~ o f ~ t h e ~ M i d l a n d ~ C o u n t i e s ~ o f ~ N o r t h ~}$ Carolina 1856. 
andere vollstïndig daraus bestehen, und keine Spur von Korund enthalten.

Die im Diluvial-Gerölle mit Gold und Edelsteinen häufig vorkommenden isolirten Krystslle von Korund, Rubin und Sapphir werde ich in dieser Untersuchung ausser Acht lassen, da ihr Vorkommen zu unbedeutend ist, um auf die in gegenwürtiger Untersuchung zu behandelnden Fragen von Einfluss za sein.

Nachdem ich nun einen kurzen Ueberblick über die geologischen Verhältnisse gegeben, unter denen das massenhafte Auftreten des Korunds beobachtet worden ist, soi es mir erlaubt, ehe ich mich zur Aufzählung der aus Korund entstandenen, oder ihn begleitenden Mineralien wende, einige Bemerkungen über die Art und Weiso mitzutheilen, wie die chemischen Analysen ausgeführt worden sind. Die grösste Aufmerksamkeit wurde der Auswahl des Materiala zur Analyse geschenkt und die dazu gewählten reinsten Fragmente unter starker Vergröøserung untersucht, etwaigo unreine oder $z$ weifelhafte Stücke stets verworfen. In einigen Fällen war es trotz aller Mühe unmöglich, vollkommen reine Substanz zur Analyse zu erhalten, eine annäbernde Analyse war aber oft zur Identificirung der Species von Wichtigkeit, und wurde deshalb ausgeführt.

Das fein gepulverte Material wurde unterm Exsiccator über Schwefelsäure getrocknet. $\mathrm{Da}$ die wenigsten der analysirten Mineralien duroh Säuren zersetzbar sind, so wurden sie durch Schmelzen mit Natriumcarbonat aufgeschlossen. Zur Bestimmung der Alkalien wurde das Mineral in einigen Fällen durch Fluorwasserstoffsäure zersetzt, in den meisten Fällen jedoch nach J. L. Smith's genaner und bequemer Methode, durch Erhitzen mit Calciumearbonat und Ammoniumchlorid.

Die durch Natriumearbonat aufgeschlossene Masse wurde in Wasser aufgeweicht, bis sie vollständig zerfallen war, und dann das Ganze in höchst verdünnter Chlorwasserstoffsäure gelöst. - Wenn die Aufschliessung vollkommen war, und das Mineral keine bestimmbaren 
Mengen mechanisch beigemengten Korunds enthielt, löste sich alles vollständig auf, und nur selten schieden sich geringe Flocken von Kieselsäure aus, die leicht za unterscheiden waren ron dem harten, schweren, sandigen Korund, Beide (im Falle beide vorhanden waren) wurden abfiltrirt, ausgewaschen, getrocknet, gegliiht und gewogen. Die Kieseløäure wurde durch verdünntes Kaliumhydroxyd aufgelöst, zuerst mit kochendem, zuletzt mit schwach durch Chlorwasserstoffsäure angesüuertem Wasser gewaschen und nach dem Trocknen und Glühen der Korund gewogen, hierauf durch Kaliumhydrosulphat aufgeschlossen und aus der Lösung die reine Thonerde wie gewöhnlich gefällt. Von der Schmelze ftir AlkalionBestimmung wurde der Rückstand, nachdem or mit kochendom Wasser auggewaschen war, auf ähnliche Weise behandelt.

Schmelzen mit Natriumcarbonat wirkt viel kräftiger auf den Korund ein, doch unglücklicher Weise wird snch durch Schmelzen desselben mit Calciumearbonat und Ammoniumchlorid ein beträchtlicher Theil desselben aufgeschlossen, so dass diese Methode zur quantitativen Hestimmung des mechanisch beigemengten Korunds nur annähornde Resultate giebt.

Die Analysen wurden dann wie gewöhnlich ausgeführt, Thonerde und Eisenoxyd zussmmen duroh Ammoniumbydroxyd gefullt und so lange gekocht, bis die Masse eine neutrale oder selbst saure Reaction zeigte. Nach dem Filtriren und Auswaschen wurde der Niederschlag wieder aufgelöst, und die nämliche Operation gewöhnlich drei bis viermal wiederholt. Nach dem Wägen der Thunerde und des Eisenoxyds wurden sie in Sulphate verwandelt, das Eisenoxyd durch Zink redueirt und mittelst Titrireng mit Kaliumpermanganat bestimmt.

Die Menge des in einem Mineral vorhandenen Eisenoxyduls wurde stets dadurch ermittelt, dass dasselbe in zugeschmolzenen Röhren unter Druck in verdiinnter Schwofelsäure aufgelöst und daun das Eisenoxydul durch Titriren mittelst Kaliumpermanganats bestimmt wurde. 
Einige mit der grössten Vorsicht ausgesuchte und dem Anschein nach ganz reine Spinelle gaben bei der Behandlang mit verdünnter Schwefelsäure in zugeschmolzenen Rühren, bei einer Temperatur von etwa 175 bis $200^{\circ}$, wobei sie sich rollständig lösten, oinen geringen unlöslichen sandigen Rückstand, der ans Korund bestand. Ich hatte gehofft, dass durch dieses Mittel andern Mineralien mechanisch beigemengter Korund sich mit Grenauigkeit bestimmen lasse, fand aber, dass such er im Zustand sehr feiner Zertheilung dadurch ziemlich leicht in Auflösung geht. Wir haben desshalb keinen Weg, die Quantität des Korunds zu bestimmen, der in einem andern Mineral mechanisch beigemengt vorhanden ist. Wir bleiben deshalb unglücklicher Weise in Zweifel über die wahre Constitation einiger Varietäten von Lesleyit und Ephesit.

Magnesia wurde immer mit $\Lambda$ mmoniumphosphat niedergeschlagen. Die Alkalien wurden zusammen als Chloride gewogen, hiersuf das Kali als Kaliumplatinchlorid abgeschieden und gewogen und dann nach der Entfernung des überschüssigen Platins und der Umwandlung der Alkalien in schwefelsaure Salze die Quantitäten von Lithion und Natron durch indirecte Analyse bestimmt. - Da jedoch, wio die Spectral-Analyse zeigte, in den meisten Fällen die Quantität des Lithions gering war, so wurden nur wenige solcher Bestimmungen gernacht.

Diess sind die wichtigsten bei den Analysen befolgten Methoden, die einer Erwähnung bedurften; ich wende mich nun zur Betrachtung der einzelnen Mineralion.

\section{Kor a nd.}

Es würde unnöthige Wiederholungen verursachen, wollte ich mich auf die Beschreibung aller Korundvarietäten einlassen; ich werde etraiges Eigenthümliche bei der Beschreibung der damit vorkommenden Mineralien erwähnen.

$$
\text { 2. Spinell. }
$$

Die Umwandlang des Korunds in verschiedene Varietäten des Spinells findet sich in mehreren Localitäten 
62 Genth: Ueber Korund, seino Umwandlungen,

a. Die interessanteste Varietat kommt von Hindostan und fand sich in einer Quantität von dorther importirten Korundkrystallen. Der Korund enthält mitunter kleine Schuppen eines röthlich-weissen Margarits. - Die Oberfläche der umgewandelten Krystalle und krystallinischen Massen ist rauh, und manche Stücke zeigen Fragmente eines rothen Orthoklases und eines dunklen Glimmers, welche bewoisen, dass sie aus Granit stammen. Die Krystalle sind zu undeutlich für Messung, doch lassen sich die Endfläcbe und ein oder zwei Pyramiden unterscheiden: sie sind von einem halben Zoll bis zu etwa zwoi Zoll gross, selten grösser. Viele sind vollständig umgewandelt, die meisten jedoch zeigen, dass die Umwandlung an der Oberfläche anfing und unregelmässig gegen den Mittelpunkt fortschritt, und enthalten oft einen Kern von bräunlichgranem spaltbarem Korund, oder Flecken desselben unregelmäвsig durch die Masse vertheilt.

Der aus dieser Umwandlung hervorgegangene Spinell hat eine schwarze Farbe, körnig krystallinische Struktur und halbmetallischen zum Glasigen sich neigenden Glanz; Strichpulver grau; schwach magnetisch.

b. Im Schacht am Weg von Unionville nach Kennett Square findet sich in Begleitung eines grau-weissen feinblättrigen Talks und grünlichen Actinolits und innig mit Chlorit gemengt ein schwarzes Mineral von Glasglanz and einer grösseren Härte als Quarz, das sich als Spinell orgab. Ea war unmöglich, ihn für die Analyse von grögserer Reinheit zu erhalten als nothwendig war zur Identificirung der Species.

c. Der durch den Chlorit von Culsagee streichende Spinellgang ist bereits oben erwähnt worden. Der Spinell ist gewöhnlich massiv, von grobkörnig bis feinkörnig; doch kommen in Drusen such Oktaeder mit Dodekaederflächen vor, die letzteren mitunter nur angedeutet durch Streifung. Die Krystalle sind gewöhnlich unvollkommen löcherig, an der Oberfläche grösstentheils umgewandelt und mit einem bräunlich-grauen glasglänzenden Mineral firnissartig überzogen. Das Innere der Krystalle, sowie 
frische Bruchflächen, zeigen den unveränderten schwarzen Spinell. Er enthält mitunter Körner von röthlich-braunem Rutil, und ist stets mehr oder weniger mit Körnern von Korund oder Chlorit gemengt, welcher letztere sich häufig strahlig von demselben ausbreitet.

d. Eine andere Varietät von Spinell von derselben Localität, hat eine dunkel lauchgrüne und grünlichschwarze Farbe, ähnlich G. Rose's Chlorospinell, und findet sich in Oktaedern und tiefgestreiften Dodekaederflächen oder körnig; in Begleitung von hellgrünem Chlorit und weissem Korund. Der Spinell ist häufig zwischen den Blättern des Chlorits eingeschlossen und enthält nicht selten Theilchen von Korund in seiner Mitte.

Strichpulver hell grau-grün.

e. In der Sammlung des Col. Willcox ist ein Exemplar von derselben Localität, welches augenscheinlich früher Korund war. Es ist $\mathbf{2}^{1 / 2}$ Zoll im Durchmesser und seine Contouren zeigen seinen Ursprung. Es besteht aus einem Kern von schwarzem Spinell mit einer Umhüllung von Chlorit.

f. Unter ähnlichen Verhältnissen habe ich vor Kurzem schwarzen Spinell mit Korund aus der Grafschaft Jancey erhalten.

g. Auf der Cullakanee Grube kommt Spinell nur selten vor. Ich habe nur ein Stück gesehen, in welchem schwarzer Spinell in Körnern und oktaedrischen Krystallen in dunkelgrünem blättrigem Chlorit vertheilt, eingewachsen war.

h. Zu Dudleyville in der Grafschaft Tallapoosa in Alabama umhüllt schwarzer Spinell Theilchen eines gelblich-weissen Korunds, die zusammen im Chlorit vorkommen.

i. Die von J. L. Smith (l. c.) gemachte Beobachtung, dass die Spinellvarietät Gahnit zu Gumuch-Dagh in Kleinasien in Begleitung von Korund vorkommt, ist mit Rücksicht auf die erwähnten Beobachtungen von vielem Interesse. 
64 Genth: Deber Korund, seine Umwandlungen,

Folgende Analysen worden auggeführt:

21 und a 2 von Hindostan, von mir selbst;

b. von Dr. G. A. Koenig;

c1, feinkörnig und $\mathrm{c} 2$ von gröberem Korn -

beide von Culsagee, von Dr. Koenig;

d, grobkürnig und krystallisirt und dunkelgrü von Culsagee, von mir selbst.

\begin{tabular}{|c|c|c|c|c|c|c|c|c|}
\hline & (a 1) & (a2) & Mittel & (b) & (o 1) & (c2) & & (d) \\
\hline Bpec.Gew. & $=4,208$ & - & - & - & $8,766-$ & 8,797 & - & 3,695 . \\
\hline $\mathrm{Al}_{2} \mathrm{O}_{3}$ & $=48,87-$ & $18,10-$ & 48,49 & 54,81 & $-60,03$ & $-62,88$ & - & 88,08 \\
\hline $\mathrm{Fe}_{2} \mathrm{O}_{3}$ & $=17,30$ & 18,17 & 17,73 & 4,10 & 8,49 & 7,78 & & 1,75 \\
\hline $\mathrm{Cr}_{2} \mathrm{O}_{3}$ & $=-$ & - & - & - & 3,23 & 1,81 & & Spur \\
\hline $\mathrm{FeO}$ & $=\mathbf{2 3 , 5 3}$ & 29,26 & 89,39 & 10,67 & 9,93 & 11,89 & & 11,02 \\
\hline $\mathrm{MnO}$ & $=$ Spar & Spur & Spur & - & - & - & & Spur \\
\hline $\mathrm{g}$ & $=6,86$ & 6,66 & 6,76 & 13,83 & 16,74 & 14,98 & & 10,29 \\
\hline $\mathrm{Si}_{2}$ & $=-$ & - & - & 1,26 & 1,14 & \multirow{2}{*}{\multicolumn{3}{|c|}{$\begin{aligned} 1,66 \mathrm{CuO} & =0,11 \\
-\mathrm{ViO} & =0,24\end{aligned}$}} \\
\hline ranc & $a=4,81$ & 4,31 & 4,31 & 16,24 & - & & & \\
\hline & $\overline{100,87}$ & $\longdiv { 0 , 4 9 }$ & 0,68 & 100,71 & $99, \widehat{96}$ & $\overline{0,41}$ & & 00,49 \\
\hline
\end{tabular}

Keins der untersuchten Muster zeigte bei der Untersuchung mit einer starken Loupe die geringste Spur von Korund, b und $\mathrm{c} 1$ und $\mathrm{c} 2$ enthielten jedoch eine Beimengung von Chlorit, Die Analyse von b hatte nur zum Zweok, auszufinden, was das glänzende schwarze Mineral sei, sie zeigto jedoch ausser der Thatsache, dass es Bpinell sei, eine andere höchst wichtige, nämlich dass dieser Spinell eine mechanische Beimengung von Korund hatte und wahrscheinlich daraus entstanden war.

Eine Betrachtung der übrigen Anslygen führte zu folgenden Resultaten:

a. Der Sauerstoffgehalt des Mittels der beiden Anslysen des Spinells von Hindostan ist in den Sesquioxyden 4,22 p.C. mehr als die Formel $\mathrm{BO} \cdot \mathrm{R}_{2} \mathrm{O}_{2}$ verlangt, welches zeigt, dass der Spinell ausser den 4,31 p.C. von der verdünnten Schwefelsäure nicht gelösten Korundz, nooh 9,05 p.C. enthielt, die in Lösung gegangen waren, und dass selbst der sorgfialtigat ausgesuchte, ans Korund ontstandene Spinell von Hindostan, wahrscheinlich noch 18,36 p.C. des ursprünglichen Minerals beigemengt enthielt. - 
c1. Nach Abzug von 0,93 $\mathrm{Al}_{2} \mathrm{O}_{3}, 0,09 \mathrm{Fe}_{2} \mathrm{O}_{3}, 0,22$ $\mathrm{FeO}$ und $1,18 \mathrm{MgO}$ für 1,14 p.C. $\mathrm{SiO}_{2}$, übereinstimmend mit der Zusammensetzung des blättrigen Chlorits von Culsagee, ist das Sauerstoffiverhältniss von $\mathrm{RO}$ and $\mathrm{R}_{2} \mathrm{O}_{3}$, welches die Spinellformel verlangt, für die Sesquioxyde um 6,67 p.C. zu hoch, was einer mechanischen Beimengung von 14,74 p.C. Korund entgpricht.

c2. Die gefundenen 1,56 p.C. Kieselsäure verlangen zur Bildung von blättrigem Chlorit $1,28 \mathrm{Al}_{2} \mathrm{O}_{3}, 0,14 \mathrm{Fe}_{2} \mathrm{O}_{3}$, $0,32 \mathrm{FeO}$ und 1,61 $\mathrm{MgO}$, nach deren Abzug die vorhandenen Sesquioryde 7,58 p.C. mehr Sauerstoff enthalten, als die Spinellformel verlangt, wodurch eine Beimengung von 16,27 p.C. Korund angezeigt wird.

d. Die Zersetzung durch verdünnte Schwefelsäure gab 0,73 p.C. Kieselsäuse mit einer Spur Korund, welche von der zur Analyse verwandten Quantität abgezogen wurden. Das Sauerstoffverhältniss vou $\mathrm{BO}: \mathrm{R}_{2} \mathrm{O}_{3}=1: 3,15$ ist nahe dem des Spinells. Der Ueberschuss von 1,57 p.C. Sauerstoff würde einer Beimengang von 3,37 p.C. Korund entsprechen.

Nach Abzug der mechanisch beigemengten Substanzen würden die verschiedenen Spinelle folgende Zusammensetzung zeigen:

$\begin{array}{lcccc} & \text { Hindostan } & \text { of Culsagee } & \text { e2 Culsagee } & \text { d Culsagee } \\ \mathrm{Al}_{2} \mathrm{O}_{3}=45,17 & 54,32 & 56,58 & 66,63 \\ \mathrm{Cr}_{2} \mathrm{O}_{3}=- & 3,96 & 2,28 & \mathrm{Spur} \\ \mathrm{Fe}_{2} \mathrm{O}_{8}=20,30 & 11,51 & 9,66 & 1,80 \\ \mathrm{FeO}=26,79 & 11,16 & 14,60 & 11,35 \\ \mathrm{MgO}=7,74 & 19,05 & 16,88 & 19,86 \\ \mathrm{CuO}=- & - & - & 0,11 \\ \mathrm{NiO}=- & - & - & 0,25\end{array}$

Diese Analysen zeigen, dass der nach Korund pseudomorphe Spinell von Hindostan und der grüne Spinell von Culsagee Gemenge der Spinellvarietäten Hercynit und Pleonast sind, während die beiden andern von Culsagee ausser diesen noch Picotit enthalter. Die Spinelle von Unionville Pa. und Dudleyville Alab. enthalten nur Spuren 
66 Genth: Ueber Korund, seine Umwandlungen,

von Chromoxyd, sind also wahrscheinlich Gemenge von Pleonast und Hercynit.

\section{Diaspor.}

An vielen Fundorten des Korunds ist Diaspor beobachtet worden, ohne Zweifel als das Resultat der Wasseraufnahme desselben; wirkliche Pseudomorphosen sind meines Wissens nirgends beobachtet worden.

J. L. Smith (l. c.) machte die sehr wichtige Beobachtung, dass aller Korund, welchen er untersuchte, wechselnde Mengen Wasser enthielt, von 0,68 bis zu 3,74 p.C., dass sich aber durch die wiederholte genaueste Untersuchung kein Diaspor noch sonstiges Thonerdehydrat nachweisen liess. --

Möchte nicht der Diaspor so ausserordentlich fein in: Korund vertheilt sein, dass er selbst mit dem besten Mikroskop nicht zu entdecken war, genau so, wie ich es so eben an den Beimengungen des Korunds im Spinell gezeigt habe? Die folgende Bemerkung, welche J. L. Smith auf S. 58 macht ist von grossem Interesse in dieser Beziehung. Er sagt: „Doch von allen gesammelten Stücken zeigen „keine so hohes Interesse, als die von im Korund einge"lagerten Diaspor. Hier siebt man beide Mineralien, ,ohne im Stande zu sein, an vielen Stellen ihre Tren"nungslinie zu unterscheiden, so allmählich ist der Ueber,gang. Nach dem in Beziehung auf Korund Gesagten, „,kann es nicht befremden, diese Verbindung von mehr "oder weniger gewässerter Thonerde mit einem Hydrat „derselben in bestimmter Zusammensetzung zu soheu." -

Der Diaspor der verschiedenen Fundorte ist so vollständig beschrieben, dass es keiner Wiederholung bedarf.

Diaspor ist mit Ausnahme der Localität in Chester, Mass., wo er in grossen Quantitäten und ron ausgezeichneter Schönheit gefunden worden ist, ein seltenes Mineral in Amerika. Dr. Isaak Lea ${ }^{1}$ ) gab in der Aca-

') Isa ak Lea. - Prooedings Acad. Nat. Sciences, Philadelphia. April 9. 1867 . 
demy of Natural Sciences of Philadelphia eine Beschreibung ausgezeichneter Krystalle, welche er zu Unionville, Pa., aufgefunden hatte. - Blos ein oder zwei Stücke fanden sich in Drusen des blättrigen Korunds von Culsagee in kleinen nadelförmigen Krystallen der gewöhnliohen Form ${ }^{1}$ ).

Ich war nicht im Stande, dieses Mineral an einer andern Localität von Nordcarolina, Südcarolina, Georgia und Alabama zu entdecken.

\section{Beauxit.}

Dieses Hydrat der Thonerde, gewöhnlich mit beträchtlichen Mengen von Eisenoxydhydrat und wasserhaltigem Thonerdesilikat gemengt, findet sich in bedeutenden Lagern im südlichen Theile von Frankreich; zuweilen schliesst es Körner von Korund ein.

T. S. $H u n t^{2}$ ) macht folgende Bemerkungen über disse interessante Thatsache: ,Durch intensive Hitze ,wird diese Substanz (Beauxit) in krystallini"schen Korund umgewandelt, der in seinen phy"sikalischen Eigensehaften dem Smirgel ähnlich „ist; aber die Gegenwart von Körnern vor Ko"rund in dem wasserhaltigen Mineral scheint zu „beweisen, dass diese Umwandlung auch bei ge"wöhnlicher Temperatur stattfinden mag." - Ich kenne keinen einzigen Fall, in welchem unter den ge. gebenen Verhältnissen Korund aus dem Hydrat hätte abgeschieden werden können; in Gegentheil, die Gegenwart von Korund im Beauxit beweist mit ziemlicher Sicherheit, dass das letztere Mineral aus Korund durch Wasseraufnahme entstanden ist, und dass die darin gefundenen Körner von Korund, Reste nicht amgewandelten Materials sind.

5. Gibbsit.

Dieses sehr seltene Thonerdehydrat ist, so viel ich finden kann, nur zweimal mit Korund zusammen beobach-

1) J. C. Trautwine, Journ. Franklin Institut. 94, 7.

2) T. S. H unt, sill. Journ. [2] 32, 288. 
tet worden, und ohne Zweifel durch Wasseraufnahme daraus entstanden; zuerst von J. L. Smitb (l. c.) zu Gumuch-Dagh in Kleinasien, wo es einen Ueberzug auf einem Korundkrystall bildet, ausserdem in der Form einer sechsseitigen Säule. Letzteres ist sehr wahrscheinlich eine Pseudomorphose von Gibbsit nach Korund. - Die zweite Localität ist Unionville, $\mathrm{Pa}$., wo er von $\mathrm{T}$. F. Seal ${ }^{1}$ ) als ein dünner Ueberzug und in warzenförmigen Inkrustationen auf Albit getunden warde. (Die übrigen zu Unionville auf Korund vorkommenden Inkrustationen sind kein Gibbsit, sondern Margarit, wie in der Folge gezeigt werden wird).

\section{Quarz.}

Sillem erwähnt, dass Quarz pseudomorph nach Korund vorkommt. Ich habe diese Paeudomorphose nie gesehen und erwähne sie nur der Vollständigkeit halber.

\section{Opal.}

Ausscheidungen von amorpher Kieselsäure finden sich an mehreren Orten zusammen mit Korund und sus ihm entstandenen Mineralien, so als Hyalit in schönen farblosen und weissen traubigen Inkrustationen anf blättrigem Chlorid und auf Korund zu Culsagee, desgleicheu zu Dudleyville, Ala., in bräunlich weissen, traubigen Inkrustationen auf blauem blättrigem Korund.

Eine der Fibrolitpseudomorphosen nach Korund von Mineral Hill, Grafschaft Delaware in Peunsylvannien, hat ebenfalls einen schwachen, glasigen, traubigen Ueberzug, der Hyalit zu sein scheint.

$$
\text { 8. Smaragdit (?) - Kolsscharufit. }
$$

Ich habe bereits die eigenthümliche Felsart erwähnt, die zu Cullakenee untergeordnet anftritt und aus Smaragdit (?), einem trikliniscben Feldspath und Kömern eines rosenrothen bis tief rubinrothen Korunds besteht, mitunter von Cyanit und Krystallen von Chromit begleitet.

1) T. F. Seal, Sill. Journ. [2] 11, 267:

צ) Sillem, Leonhard and Broun's Jahrbach 1851. 385. 
Der Smaragdit hat sehr undeutliche Form, doch lassen sich häufig stumpfe Winkel wie bei Hornblende beobachten. Seine Farbe ist ron smaragd- bis grasgrün, sich ins Graugrünliche und Graue neigend.

Härte $=5,5$. - Specifisches Gewicht der grasgrünen Varietät $=3,120$.

Vor dem Licht leicht zu grünlichem Glas schmelzbar, wobei die äussere Flamme gelb gefärbt wird.

Das mit grosser Vorsicht ausgewählte Material der grasgrünen Varietät, und anscheinend frei von Feldspath, warde von Thomas M. Chatard mit folgendem Resultat untersucht:

$$
\begin{aligned}
& \mathrm{SiO}_{3} \ldots \ldots=\$ 5,14 \text { enthält Sauerstoff }=24,07 \quad=2,06
\end{aligned}
$$

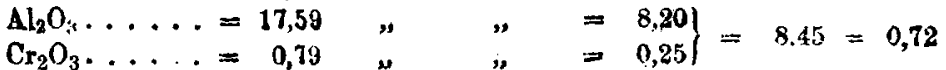

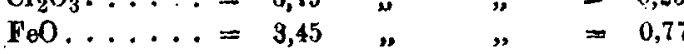

$$
\begin{aligned}
& \text { NiO..... " " " }=0,21 \quad \Rightarrow 0,04 \\
& \text { MrO .... " }
\end{aligned}
$$

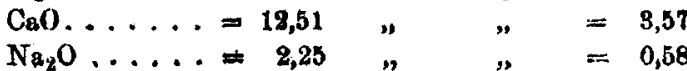

$$
\begin{aligned}
& \mathrm{K}_{2} \mathrm{O} \ldots \ldots=0,36 \quad " \quad \Rightarrow \quad=0,06 \\
& \text { Glühveriust } \ldots=\frac{1,34}{100,33}
\end{aligned}
$$

Diese Zusammensetzung entepricht sehr nahe der Formel: $4 \mathrm{RO}^{1}$ ), $3 \mathrm{SiO}_{2}+\mathrm{R}_{2} \mathrm{O}_{3}, \mathrm{SiO}_{2}$, und stimmt ganz mit der des Kokscharoffits, sie hat keine Aehnlichkeit mit der des Arfvedsonits, wozu dieses Mineral von $S$ h apard als Chromarfvedsonit (l. c.) gezählt wird. J. Id. Smith (1. c.) hat neuerdings eine grüne und eine schwarze Varietät untersucht, in welcher letzteren ein Theil der 'Thonerde durch Fisenoxyd substituirt ist, hält aber beide irrthümlich für Zoisit.

An demselben Fundort und oinigen anderen Korundlocalitäten kommen noch andere Hornblendevarietäten vor, die mitunter tief in die Masse des Korands eindringen.

1) $\mathrm{RO}$ mit Winsohluse von $\mathrm{R}_{2} \mathrm{O}$ in dieser und allen folgenden Analysen. 


\section{Zoisit.}

Zoisit ist mehrmals in Begleitung des Korunds beobachtet worden, zuerst von G. Rose (l. c.) zu Mramorsk im Ural, sodann zu Unionsville zugleich mit Turmalin und Euphyllit von B. Sillimann ${ }^{1}$ ) und von ihm als Unionit beschrieben; das ausgezeichnetste Vorkommen ist jedoch das zu Cullakenee, entweder in dem so eben beschriebenen graulichgrünen oder grasgrünen Smaragdit (?), oder direct mit Korund. Hier findet er sich in Krystallen, jedoch gewöhnlich in stängligen oder säulenförmigen, kompakten, spaltbaren Massen von weisser und graulich oder grünlichweisser Farbe. Viele der Stücke zeigen unwiderleglich, dass der Zoisit das Product der Zersetzung des Korunds ist. Der rosenrothe blättrige Korund bildet Schnüre oder Gänge in dem hornblendeartigen Gestein und ist oft von einem dünnen Ueberzug von weissem Zoisit umgeben, der den Anfang der Umwandlung bildet, dieser wird dieker und dicker, bis er den ganzen Gang ausfüllt, zuerst dicht, dann in spaltbaren stängligen Massen, während der Korund ganz verschwunden ist. - Andere Stücke zeigen einen blänlich grauen Korund auf einer Seite in stängligen Zoisit, auf der anderen in blättrigen Margarit umgewandelt. Viele enthalten noch Kerne von unverändertem Korund durch die Zoisitmasse vertheilt.

Folgende Varietäten wurden untersucht:

a) ein blättriger grünlichweisser aus der Umwandlung von rosenrothem Korund entstandener, von Dr. Georg A. Koenig;

b) ein weisser ins Graue sich neigender stängliger Zoisit, der aus bläulichgrauem Korund entstanden war und noch Korundkerne einschloss, von mir;

c) zur Vergleichung gebe ich die Analyse des Zoisits von Unionville (Silliman's Unionit) von Georg F. Brush ${ }^{2}$ ).

1) B. Silliman, Sill. Journ [2] 8, 384.

2) G. F. Bru\&h, Sill. Journ. [2] 26, 69. 


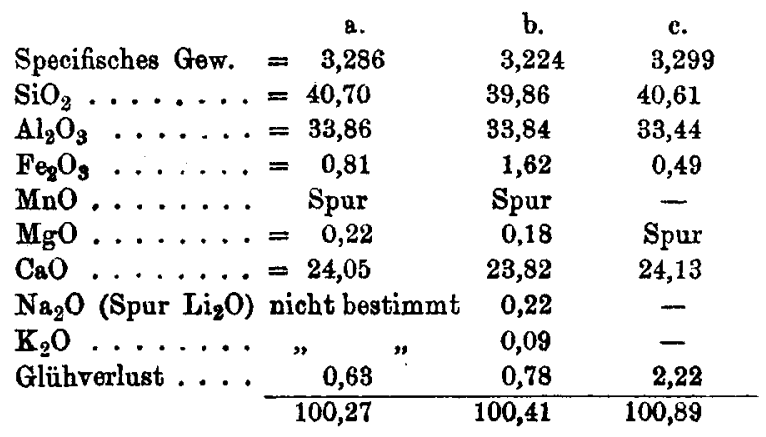

Die Sauerstoffverhältnisse von $\mathrm{RO}: \mathrm{R}_{2} \mathrm{O}_{3}: \mathrm{SiO}_{2}$ sind wie folgt:

$$
\begin{aligned}
& a=6,96: 16,02: 21,71=1: 2,30: 3,12 \\
& b=6,84: 16,25: 21,26=1: 2,34: 3,06 \\
& c=6,89: 15,74: 21,66=1: 2,28: 3,14
\end{aligned}
$$

Alle diese Analysen des den Korund begleitenden Zoisits zeigen einen geringen Ueberschuss von Thonerde, wenn man das Verhältniss von 1:2:3 als richtig annimmt. Sollte dies, was wahrscheinlich ist, einer geringen Beimengung von Korund zuzuschreiben sein, so würde a 4,50 p.C., $b-5$ p.C. und $c-4,21$ p.C. davon enthalten.

\section{Feldspäthe.}

Mehrere Feldspathvarietäten kommen unter Verhältnissen, die ron grossem Interesse sind, zusammen mit Korund vor.

a) Eine weisse, grauliche und röthliche Varietät, die In dianit genannte Varietät des Anorthits, wurde vom Grafen Bournon als die Gangmasse des Korunds im Carnatic angegeben. Begleitende Mineralien sind Cyanit und Granat. Er wurde bereits vor mehr als 70 Jahren von Chenevix analysirt und neuerdings mit fast gleichern Resultat von G. J. Brush' ), wenn wir die geringen Mengen von Natron, die Ersterer übersah, ausser Acht lassen. Das Sanerstoff-

1) G. F. Brash, Dana's Descriptive Mineralogy 1868. 399. 
verhältniss von $\mathrm{RO}\left(1 / 6 \mathrm{Na}_{2} \mathrm{O}+5 / 6 \mathrm{CaO}\right): \mathrm{Al}_{2} \mathrm{O}_{3}: \mathrm{SiO}_{2}$ ist $=1: 3: 4$.

b) Unter dem Namen Barsowit beschrieb G. Rose einen anderen körnigen Feldspath von schneeweisser Farbe, der zu Barsowskoi bei Kyschtimsk im Ural die Gangmasse des Korunds bildet. Seine Bestandtheile haben folgendes Sauers voflisverhältniss: $\mathrm{CaO}: \mathrm{Al}_{2} \mathrm{O}_{3}: \mathrm{SiO}_{2}=1: 3: 5$. - Teh habe nur ein Stiuck gesehen, welches aus einem körnigen feldspathigen Mineral bestand, in welehem kleine Krystalle von grauem Korund in. Doppelpyramiden eingeschlossen waren. Beim Zerschlagen eines Stücks liessen die Korundkrystalle einen glatten Abdruck im Barsowit zurüek, als ob der letztere noch in plastischem Zustand gewesonn wäre, als die Korundkrystalle bereits gebildet waren.

c) Eine schneeweisse und bläulichweisse blättrige Varietät eines Feldspaths, welcher feine Zwillingsstreifung auf den Spaltungsflächen zeigt, findet sich mit grünlichschwarzer Hornblende, die ebenfalls deutlich einen Winkel von nahezu $124^{\circ}$ zeigt, zu Cullakenee; ich konnte aber keinen Korund in dem blättrigen Mineral entdecken. Die Analyse gab die Zusammensetzung des Andesits. (Analyse e 1. von Dr. G. A. Koenig.)

Mit ihm zusammen findet sich ein körniger und dichter Feldspath, der wahrseheinlich damit identisch ist und Krystalle von Korand durch die Masse vertheilt hat. In einem frisehen Brucbstück ist der Korund kaum zu bemerken, in theilweise verwitterten Stücken ragen die Korundkrystalle, manche bis nahezu einen Zoll im Darchmessur nervor. Sie sind sehr rauh, als ob sie zerfressen wären, nnd bei vielen ist ein glimmerähnliches Mineral (wahrseheinlich Damourit) vorhanden, welches nicht nur die Aussenseite der Krystalle bedeckt, sondern sogar bis ins Innere derselben eindringt.

Mit dem massiven grauen Korund von Cullakenee, der, wie ich oben angab, theilweise in Zoisit und Margarit umgewandelt ist, findet sich, jedoch selten, ein feinkörniger, zäher, weisser Feldspath, der ganz das Ansehen von 
Zucker hat, und wahrseheinlioh aus Korund entatanden ist. Analyse (c 2.) durch Thomas. M. Chatard.

$$
\text { (c.1) }
$$

Spec. Gew. $=2,611$ - Sauerst.

$\mathrm{SiO}_{2} \ldots \ldots=57,29 \quad 30,55$

$\mathrm{Al}_{2} \mathrm{O}_{3} \ldots=26,52$

$\mathrm{Fe}_{2} \mathrm{O}_{3} \ldots \ldots=0,21$

$$
12,36
$$$$
0,06\}=12,42
$$

$\mathrm{MgO} . . . .=0,15$

$\mathrm{CaO} \ldots \ldots=7,80$

$\mathrm{Na}_{2} \mathrm{O} \ldots=6,75$

$\mathrm{K}_{2} \mathrm{O} \ldots \ldots=0,33$

Glühverlust $=\frac{1,43}{100,48}$ (c 2)

2,610 - Szuerst.

$58,41 \quad 31,15$

$25,93 \quad 12,08$

$0,38 \quad 0,11\}=12,10$

$0,18 \quad 0,07$

5,82

6,45

2,10

$\frac{0,93}{100,20}$

Das Sauerstoffverhältniss der beiden Analysen ist wie folgt:

$$
\begin{aligned}
& \left.\mathrm{RO}: \mathrm{R}_{2} \mathrm{O}_{3}: \mathrm{SiU}_{2} \text { in (o } 1\right)=4,09: 12,42: 90,55=0,99: 3: 7,51 \\
& \mathrm{RO}: \mathrm{R}_{2} \mathrm{O}_{3}: \mathrm{SiO}_{2} \text { in (c 2) }=3,74: 12,19: 31,15=0,93: 3: 7,67
\end{aligned}
$$

iibereinstimmend mit der Formel für Andesit $=\left(\mathrm{Na}_{2} \mathrm{O} . \mathrm{CaO}\right)$ $\mathrm{SiO}_{2}+\mathrm{Al}_{2} \mathrm{O}_{3} \cdot 3 \mathrm{SiO}_{2}$.

d) Eine andere feinkörnige leicht zerreibliche Varietät von Feldspath, sehr ähnlich dem Oligoklas von Chester, Mass., findet sich ebenfalls zu Cullakenee. Dies ist wahrscheinlich der von J. L. Smith (l. c.) als Andesit beschriebene Feldspath, dessen Analyse jedach sehr nahe das Sauerstoffverhältniss des Oligoklases gibt und obne Zweifel das letztere Mineral ist.

e) Der von Smith und Brushi) analysirte Soda-Oligoklas kommt in Begleitung von Euphyllit mit Korund bei Unionville, Pa., vor.

tin Stück in der Universitätssammlung von der nämlichen Lrocalität, bestoht aus einem körnigen, gelblichen oder bräunlichweissen Oligoklas, dessen kieine Spaltunggflächen mitunter feine Streifung zeigen. Er enthält, dureh seine Masse vertheilt, kleine Flecken von körnigem grauem Korund, mit einem harten schwarzen Mineral, das wahrseheinlich Spinell ist, gemengt. - Der Korund ist an manchen Stellen in ein weiches kryptokrystallinisches, etwas

1) Smith und Brugh, Sill. Journ. [2] 15, 211 and 16, 44. 
74 Genth: Ueber Korund, seine Umwandlungen,

perlmutterglänzendes weisses oder grauweisses Mineral umgewandelt, welches Margarit zu sein scheint; er ist häufig vom Oligoklas durchdrungen, und sieht aus, als ob er ein Rest wäre, zurückgeblieben bei seiner Umwandlung in Oligoklas und andere Species. Eine Analyse dieses Oligoklases durch Thomas M. Chatard gab folgende Resultate:

$$
\begin{aligned}
& \mathrm{SiO}_{2} \ldots \ldots=59,35 \text { enthält Sanerstoff } 31,65 \\
& \mathrm{Al}_{2} \mathrm{O}_{3} \ldots=24,16 \quad, \quad, \quad 11,26 \\
& \left.\mathrm{Fe}_{2} \mathrm{O}_{3} \ldots=0,61 \quad " \quad, \quad 0,18\right\}=11,44 \\
& \mathrm{MgO} \ldots \ldots=0,34 \quad " \quad \text { " }, 0,14
\end{aligned}
$$

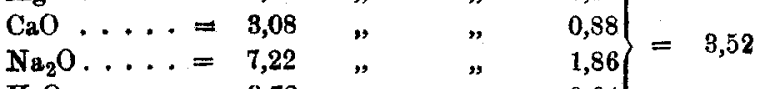

$$
\begin{aligned}
& \mathrm{K}_{2} \mathrm{O} \ldots=3,78 \quad, \quad, \quad, \quad 0,64 \\
& \text { Glühverlust . }=\frac{1,96}{100,50}
\end{aligned}
$$

Das Sauerstoffverhältniss von $\mathrm{RO}: \mathrm{R}_{2} \mathrm{O}_{3}: \mathrm{SiO}_{2}=3,52$ : $11,44: 31,65$ ist $=0,92: 3: 8,30$ oder nahezu $=1: 3: 9$, in Uebereinstimmung mit der Oligoklasformel $=2\left(\mathrm{~K}_{2} \mathrm{O}, \mathrm{Na}_{2} \mathrm{O}\right.$, $\mathrm{CaO}) 3 \mathrm{SiO}_{2}+2\left(\mathrm{Al}_{2} \mathrm{O}_{3}, 3 \mathrm{SiO}_{2}\right)$.

f) Der gelblichweisse, oben erwähnte, die Pseudomorphosen von Fibrolit nach Korund enthaltende Feldspath von Mineral Hill, Grafschaft Delaware, Pa., scheint ebenfalls Oligoklas zu sein.

g) Der weisse körnige Feldspauı aus der Nachbarschaft von Unionville, $\mathrm{Pa}$., ist von Brush und $\mathrm{Weld}{ }^{1}$ ) analysirt worden, welehe fanden, dass er ein Albit mit einem geringen Kalkgthalt ist. Fr bildet häufig die Matrix von grauen Korundkrystallen und wird von Euphyllit (?) begleitet. Die Korundkrystalle sind rauh und unregelmässig und stets mehr oder weniger von Euphyllit überzogen, umhüllt oder darin umgewandelt, ausserdem in ein weiches anscheinend amorphes Mineral, das eine Varietät von Margarit zu sein scheint, von dem ich aber nicht hinreichend Material für eine Analyse besass.

Es ist eine höchst interessante Frage, ob $\mathrm{d}^{\mathrm{a}} \mathrm{e}$ mit dem Korund zusammen vorkommenden Feldspäthe das Pro-

1) Brush und Weld, Sill. Journ. [2] 8, 390 . 
duct der Umwandlung des ersteren sind. Die vorliegenden Beobachtungen sind nicht hinreichend, um eine entscheidende Antwort geben zu können. Es kann jedoch kaum einem Zweifel unterliegen, dass einige derselben, zum Beispiel der körnige zuckerähnliche Andesit von Cullakenee, aus Korund entstanden sind. Viele andere sind wahrsoheinlich ebenso entstanden, aber zur Zeit der Bildung krystallisirte ein Ueberschuss der vorhandenen Thonerde wieder als Korund heraus.

Aehnliche Erscheinungen finden sich bei einigen anderen Substanzen, die ich bier erwähnen will, namentlich bei den Korundkrystallen in einer Matrix von Turmalin and den schönen, vollkommen ausgebildeten Krystallen von Korund in Chlorit von der Culsagee Grube.

\section{Tarmalin}

Turmalin ist einer der gewöhnlichsten Begleiter des Korunds; so findet er sich zu Kassoibrod im Ural, auf Naxos in Griechenland, zu Chester, Mass., Unionville, Pa., auf der Culsagee Grube, zu Dudleyville, Ala., und mehreren anderen Orten.

a) Zu Unionville tritt er häufig mit Korund oder den aus ihm entstandenen Mineralien auf, und bildet unregelmässige Massen von der Grösse kleiner Körner bis zu einigen Zollen im Durchmesser, namentlich im blättrigen Margarit, oder mit Zoisit und Euphyllit. Er zeigt manchmal prismatische Flächen, gewöhnlich aber ist er körnig und bildet die Ausfüllungsmasse zwischen dem Korund. Fin sehr interessantes Vorkommen von derselben Localität erwähnt Isaac Lea (l. c.). Ein Krystall eines durchsichtigen grünen Turmalins durchdringt die Mitte eines Diasporkrystalls, beide von blättrigem perlmutterglänzendem Emerylit (Damourit, Genth) eingeschlossen. Aehnlich ist das Auftreten langer, dunkelgrüner Turmalinkrystalle in dem pseudofaserigen, weissen Damourit. - Diese Krystalle sind wahrscheinlich bei der Unwandlung von Korund entstanden, oder der schwarze Turmalin löste sich auf and schied sioh im Diaspor und Damourit wieder in 
Genth: Ueber Korund, seine Umwandlungen,

Krystallen aus, in ähnlicher Weiso, wie Apophyllit unter Drnck in Wasser gelöst, beim Erkalten anskrystallisirt, wie Wöhler durch sein bekanates und wichtiges Experiment gezeigt hat.

b) Höchst wichtig ist das Vrorkommen des Turrasins mit dem Korund auf der Culsagee Grube.

Dort findet sich schwarzer Turraalin, welcher mehr oder weniger häutig Krystalle von weissem oder gelblichweissem Korund unregelmässig durch seine Masse vertheilt enthalt. Chloritblätter durchsetzen mitunter den Turmalin.

Die Korundkrystalle onthalten Theilchen von Turmalin eingemengt und umgekehrt; im Gan\%en jedoch erscheint der Turmalin mehr als Matrix des Korunds. Mitunter findet ein fast unbemerkbarer Uebergang von körnigem Korund in Turnalin statt. Hauptsächlich erwähnenswerth ist ein Stück eines schwarzen str̈ngligen Turmalins mit einem glimmerartigen Mineral (wahrgeheinlich Margarit) und grauweissem Korund. An einew Krystall besteht das obere Ende des stängligen Turmalins aus Korund, der auch theilweise in denselben eindringu.

Das zweite Exemplar von derselben Grube ist eine Pseudomorphose von Turmalin nach Korund. Es besteht sus einem Fragment eines Krystalls von rötblich-grauem Korund won otwas mehr als zwei Zoll Höhe und etwa zwei Zoll im Durchmeaser. Fs zeigt drei Flächen der hexagonalen Säule mit einer Pyramidenflüche. Am oberen Theil des Krystalls ist fast aller Korund in schwarzen Turmalin ungewandelt und nur eine zwischen $1 / 8$ und $1 /$ 7oll dicke Schaale von Korund ist iibrig geblieben; $8 m$ unteren Theil des Krystalls ist der Korund, jedoch gemengt mit 'Turmalin, noch einen Zoll dick. Blätter vou Chlorit durchdringen den Turmalin and den Korund.

c) Auf der Cullakenee Grube kommt der Korund nur selten vor; er ist in Begleitung ron schwach rïtblicbem Margarit und einem Mineral in dünnen prismatischen, längsgestreiften Krystallen von bräunlich gelber Farbe, das manchen Varietaten von Epidot ähnlich sieht, aber in 
zu geringer Menge vorbanden war, um eine gensuere minoralogische Bestimmung davon zu machen.

Die iibrigen mir bekannt gewordenen Vorkommnisse von Turmalin mit Korund in Nordearolina, Georgia und Alabama zeigen keine erwähnenswerthen Eigenthümlichkeiten.

\section{Fibrolit.}

Seit langer Zeit war Fibrolit als Begleiter des Korunds in der Carnatic in Indien und aus der Nachbarschaft von Canton in China bekannt; eine Varietät, welche während der Steinperiode vielfach von den Celten zur Anfertigung verschiedener Werkzeuge gebraucht wurde, findet sich unter Anderen in der Nachbarschaft von Chavagnac und Ourouze in Frankreich, wo er zusammen mit Glimmer, Cyanit und rothem und blauem Korund vorkommt.

Eine der interessantesten Localitäten fincet sich bei den Fällen des Jantic bei Norwich in Conuecticuty), wo kleine Krystalle von Sapphir vollständig in Fibrolit eingehüllt sind. Dies int zweifelsohne Folge des theilweisen Umwandlung von Korund in Fibrolit.

Wie ich bereits oben orwähnte, giebt es cin ganz ähnliches Vorkommen in einem feldapathigen Gestein zu Mineral Hill, in der Grafschalt Delaware in Pennsylvanien. Die Korundkrystalle sind rauhe sechsseitige, an beiden Enden sich zuspitzende Prismen, von $1 / 2$ bis zu $1 \frac{1}{2}$ Zoll Läng and einer Dicke ron $1 / 8$ bis zu einem Zoll. Sie haben verschiodene Farben von weiss bis braun, gewöhnlich von euner reichen nelkenbraunen Nuance; viele haben weisse oder farblose sechsstrahlige Sterne auf der Endfäche. Diese zeigen unter Vergrösserung stets eine l'aserige Structur. - In Fällen, wo die Umwandlung des Korunds eben anfëngt, hat er nur einen schwachen Ueberzug, oft nicht disker als ein Firniss, von einem graulich-weissen Mineral. Dieses zeigt bei starker Vergrbsserung' Glasg'anz und eine

1) C. U. Shopard, sill. Jourd. (2) 4, 380 . 
78 Genth: Ueber Korund, seine Umwandlungen,

faserige oder vom Korund anggehende strahlige Structur. Viele der Krystalle baben noch einen Korn von Korund, andere aind total umgewandelt und jede Spur dosselben ist vorschwundon, und Krystalle mit einer verworren faserigen Structur, Pseadomorphosen von Fibrolit nach Korund, sind geblieben.

Nur mit grossen Schwierigkeiten war ich in Stande, reines Matorial für die Analysen auszulesen, welche folgendo Resultate ergaben:

Spec. Gew. $=3,286$.

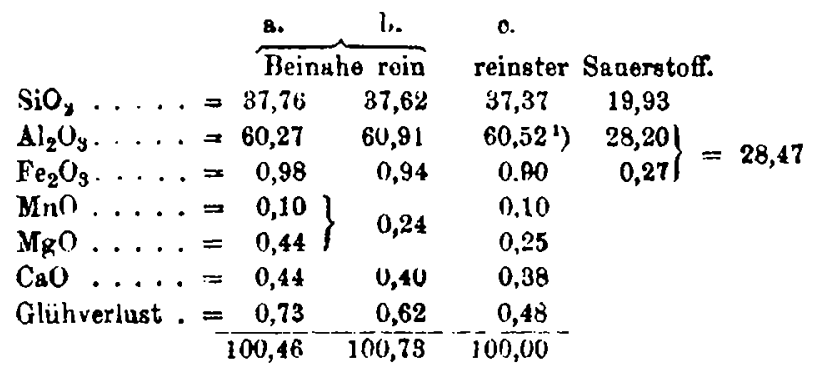

Das Sacuerstofíverhältnigs von $\mathrm{R}_{2} \mathrm{O}_{3}: \mathrm{SiO}_{2}$ ist $1,43: 1=$ 3:2, entsprechend der Formel $\mathrm{Al}_{2} \mathrm{O}_{3}, \mathrm{SiO}_{3}$.

Fibrolit fundet sich ganz in der Nachbarschaft im Staate Delaware und der Grafschaft Delaware in Pennsylvanien an verschiedenen Orten innerhalb der Serpentinregion, und mindestens ein Theil desselben scheint aus der Unwandlung von Korund entstanden zu soin. Ich wünschte namentlich die Aufmerksamkeit auf eino Varietät zu lenken, die in der Grafschaft Delaware, Pa., vorkommt, und zwar zwischen Mcdia und dem Asyl für geistesschwache PerBonen. Auf der frischen Bruchfläche kann der Seidenglanz seiner F'asern leicht beobachtet werden, er hat eine schieferige Structur, - d weisse und hellbläuliche Krystalle von Cyanit und von braunem Staurolit sind darin eingeschlossen, die letzteren oft in Zwillingen. Das ganze Vorkommen erinnert lebhaft an die bekannten Staurolit- und Cyanitkrystalle im Paragonitschiefor vom St. Gotthardt.

j) Aus der Differenz. 
Ein ähnlicher Fibrolitschiefer ist in der Nachbarschaft der Culsagee Grube in der Grafschaft Macon, Nordcaroliva beobachtet worden.

Unter fünfzig Korundkrystallen von Laurens District in Südcarolina, die zum Theil in Damourit umgewandelt waren, fand ich einen zerbrochenen Krystall, dessen Aussenseite zu Fibrolit umgeündert war. Er bestand aus einem unregelmässigen hexagonalen Prisma, $\% / 8$ Zoll lang und nicht ganz einen halben Zoll dick, mit einem Kern von unverändertem Korund von $1 / 4$ Zoll im Durchmesser. Der Fibrolit hat eine strahlige Structur von der Oberfläche nach dem Kern zu, und seine Oberfläche besteht aus einem krystallinischen Aggregat von faserigem Fibrolit mit einigen Blättchen von Damourit.

Ich will hier noch ein sehr interessantes Stück erwihnen, welches vor vielen Jahren zu Germantown bei Philadelphia gefunden worden ist. Es besteht aus körnigem Quarz mit Streifen eines grau-weissen faserigen F.brolits von $1 / \%$ bis $3 / 8$ Zoll Breite und weniger als einer Linie Dicke. Die Mitte einzelner dieser Streifen bosteht aus blättrigem blauem Cyanit. - Es ist unmöglich, zu entscheiden, ob dieses pin Fall von Parsmorphismus ist, in welchem das monoklinische Thonerdesilicat, $\mathrm{Al}_{2} \mathrm{O}_{3}$, $\mathrm{SiO}_{2}$ in das triklinische sich verändert hat, oder ob beide unabbängig von einander in ihrer jetzigen Form aus demselben Medium herauskrystallisirten.

\section{Cy n nit.}

Cyanit ist ein sehr gewöhnlicher Begleiter des Korunds. Er findev sich an verschiedenen ausländischen Localitäten, so z. B. am St. Gotthardt, zu Petschau in Böhmen, Frankreich, China, Indion u. 8. $w$.

Er ist eines der wichtigsten Producte der Umwandlung von Korund. Ich babe die Umwandlung des Korunds in Fibrolit etwas weitläufiger behandelt, da wir bei ihm, einem in seiner chemischen Zusammensetzung identischen Körper, wirkliche Psendomorphosen besitzen, welche beim Cyanit bis jetzt nicht heobschtet sind, wahrscheinlich 
nicht, weil durch seine breitblättrige Structur jede Spur der frtiheren Gestalt verwischt worden ist. Von grosser Wichtigkeit sind deshalb solche Stücke, in denen sich noch ein Kern von Korund nachweisen lüsst.

a) Zu Litchfield und Washington, Conn., sind Rollstücke von Cyanit gefunden worden, welche Korund und Diaspor ei.sehliessen. Durch Prof, Brush erhielt ich ein schönes und höchst instructives Stück von Newton, Conn., welches aus unregelmässig geordneten blättrigen Massen von grauem, bläulichweissem and blauem Korund besteht. An manchen Stellen, und namentlich wo die in verschiedener Riohtung laufenden Blätter sich berühren, findet sich ein weisses oder gelblichweisses glimmerartiges Mineral (Damourit?), in ihm ist manchmal Diaspor eingeschlossen, und an einer Stelle in inniger Bertihrung mit dem Cyanit ein abgerundetes Fragment schwach röthlichen Korunds.

b) Fin zweites Stück ron Swannanon Gap, in der Grafsehaft Buncombe, Nurdcarolina, besteht aus einem Bruchstück einer hexagonalen Säule von Korund von tief. blauer und weisser Farbe and vollkommener rhomboedrischer Spaltbarkeit. Die Oberfäche sioht zerfressen aus, und ist in inniger Berührung mit den daraus entstandenen Mineralien, einem hell bläulich-weissen Cyanit und Damourit.

c) Ein drittes Stück kommt aus der Grafsebaft Wilkes in Nordearolina. - Es besteht aus einem grob breitblättrigen unreinen bläulich grünen Cyanit in Krystallen and krystallinischen Massen, manche der Blättern sind 1 bis $\left.1\right|_{2}$ Zoll breit. Der Korund ist in kleinen Fragmenten und Körnern dureh die Masse des Cyanits vertheilt, von grauer bis zu röthlich-branner Farbe und die charakteristische Streifung mitunter dentlich zeigend. Eine kleine Quantität von Damourit ist ebenfalls vorhanden.

Ich will hier noch einige Punkte in Hinsicht auf das Vorkommen von Korund in den Grafschaften Gaston und Rutherford, Nordcarolina, erwähnen, welche in naher Beziehung zu dem so eben Erwähnten stehen, muss mir aber erlauben, auf einige Thatsachen hinzuweisen, die erst im 
weiteren Verlauf dieser Untersuchung in Betrachtung gezogen werden.

Zu Crow der's und Clubb's Mountains in der Grafschaft Gaston, Nordcarolina, sowie an einer neuerdings aufgefundenen Isocalität in der Grafschaft Rutherford findet sich Korund massiv oder ir krystallinischen Stücken, die zuweilen die hexagonale Form zeigen. Seine Farbe ist von tief Blau bis zu einem unreinen Purpur oder graublau mit Weiss gemengt. Der unzersetzte Korund ist zuweilen eisenhaltig und enthält stets durch seine ganze Maske vertheilt Rutilkrystalle von verschiedener Grösse.

Der Korund ist zuweilen in dichten Margarit umgewandelt, welcher die blauen Krystalle umhüllt, gewöhnlich aber in Cyanit und Damourit, welche von Gold, körnigem Quarz u. s. w. begleitet werden. Diese Umwandlung jedoch geschieht häufig viel weiter und keine Spur von Korund bleibt übrig, oft nichts als schlackenartig aussehende Massen, in deren Höhlungen sich Krystalle von Cyanit and ron glänzendem Rutil zeigen, in der Regel von schwärzlichbraunem Limonit überzogen. Mit ihnen finden sich zwei neue Producte aus der Zrersetzung des Korunds, nämlich Pyrophyllit und Lazulit.

Obgleich meînes Wiscens Korund niemals dort vorgekommen, so ist es dennoch höchst wahrscheinlich, dass die bei Graves Mountain in der Grafschaft Lincoln in Georgia in einem sandigen Quarz mit Rutilkrystallen vorkommenden Mineralien, Pyrophyllit, Cyanit und Lazulit, ebenfalls aus Korund entstanden sind, so wie auch die sternförmig strahligen und schiefrigen Pyrophyllite in den Grafschaften Montgomery, Randolph, Moore, Chatham und Orange in Nordcarolina und Chesterfield, District in Südcarolina.

Ein sehr ähnliches Zusammenvorkommen von Cyanit, Pyrophyllit, Damourit, Lazulit, Rutil und Hämatit findet sich zu Horrsjöberg im District Elfsdalen in Wermland and Westana in Sehweden, und es kann kaum ein Zweifel über die Bildung dieser thonerdehaltigen Minerallen aus Korund vorhanden sein. 


\section{Staurolit.}

Mit dem aus Korund entstandenen Damourit der Culsagee Grube in Nordcarolina finden sich selten braune Körnchen eines etwas glasglänzenden Minerals; sie sind dicht, von unregelmässiger Form und zeigen keine Spur einer krystallinischen Struktur oder Form. Ihr specifisches Gewicht fand ich $=3,711$ und ihre Zusammensetzung als die des Staurolits. Sie enthielten:

\begin{tabular}{|c|c|c|}
\hline $\mathrm{SiO}_{2}$ & $=27,91$ enthält Sanerstotf & 14,49 \\
\hline $\mathrm{AlO}_{3}$ & $=52,82$ & $24,74\}=26,8$ \\
\hline $\mathrm{Fe}_{2} \mathrm{O}_{3}$ & $=\quad 0,87$ & 2,06 \\
\hline $\mathrm{FeO}$ & $=7,80$ & 1,73 \\
\hline $\mathrm{MgO}$ & $=3,28$ & $1,31\}$ \\
\hline $\mathrm{MnO}$ und $\mathrm{CaO}$ & $=$ Spuren & \\
\hline Glühverlust & $=1,59$ & \\
\hline
\end{tabular}

Das Sauerstoffverhältniss von $3,04: \not 6,80: 14,49$ ist $=1: 8,8: 4,8$ oder nahezu wie $1: 9: 5$, entsprechend der Formel :

$$
2 \mathrm{RO} . \mathrm{SiO}_{2}+2\left(3 \mathrm{R}_{2} \mathrm{O}_{3}, 2 \mathrm{SiO}_{2}\right)
$$

15. Pyrophyllit.

T. S. Hunt ${ }^{1}$ ) sagt in seinen "Chemischen und Mineralogischen Beziehungen der metamarphischen Felsarten" "das letzte Glied dieses erschöpften Vorgangs "scheint dureh die Disthen- (Cyanit-) and Pyro"phyllit-Felsarten, welohe in einzelnen Regionen „,krystallinischer Gesteine vorkammen, vertreten "zu sein."

Ich habe im Capitel "Cyanit" darauf hingedeutet, dass der in mehreren Grafschaften von Nordoarolina, Südcarolina und Georgia und anderweitig vorkommende Pyrophyllit aus der Umwandlung des Cyanits entstanden ist, vielleicht an $\mathrm{Al}_{2} \mathrm{O}_{3}, \mathrm{SiO}_{2}-\mathrm{Al}_{2} \mathrm{O}_{3}, 3 \mathrm{SiO}_{2},+\mathrm{H}_{2} \mathrm{O}$.

Diese Ansicht wird durch die van F. Sandberger ${ }^{2}$ )

1) T. S. Hunt, Sill. Journ. [2] 36, 222.

2) F. Sandberger, Leonhard-Bronn's Jahrbuch 1855.315. 
gemachte Beobachtung von Pseudomorphosen von Pyrophyllit nach Cyanit von Villa Rica in Brasilien bekräftigt.

Einige andere wasserhaltige Thonerdesilicate; welche mit Korund oder aus Korund entstandenen Mineralien zusammen vorkommen, sind wahrscheinlich auf ähnliche Weise gebildet worden, zum Beispiel das im südlichen Frankreich den Bauxit tagleitende, der den Diaspor zu Schemnitz einschliessende Dillnit, und einige andre, deren Identität noch nicht hinreichend festgestellt worden ist. Sie sind meistens amorph und ihre Beziehungen zum Korund sind nicht markirt genug, um länger bei ihnen zu verweilen.

\section{Damourit.}

Dieser Name wurde von Delesse einem in feinen Schuppen vorkommenden glimmerartigen Mineral beigelegt, welches zu Pontivy in der Bretagne die Gangmasse des Cyanits bildet.

Aus dem Folgenden geht hervor, dass Damourit eins der wichtigsten Produkte der Umwandlung des Korunds, und entweder direct aus ibm entstanden ist, oder indirect, indem der Korund zuerst in Cyanit oder Fibrolit übergeführt wurde, welche letztere dann eine weitere Umwandlung in Damourit erfuhren.

Es giebt kaum in Mineral, welehes in so verschiedenen Formen auftritt, und es ist deshalb sehr oft unmöglich, es ohne Analyse zu bestimmen.

S. P. Sharploss ${ }^{1}$ ) war der Erste, welcher zeigte, dass das mit dem Diaspor bei Unionville in Newlin Township in der Grafschaft Chester, $\mathrm{Pa}$., vorkommende glimmerartige Mineral, welches man stets für Margarit (Emerylit) gehalten hatte, Damourit sei.

Bei Unionville finden sich die folgenden Varietäten:

a. Kryscalle, welche bäufig die Seitenflächen und mitunter die Endflächen deutlich zeigen; sie orscheinen als seahaseitige Platton, die aber wahrscl.ainlich rhombisoh

3) 8. P. Sharpless, Sill. Journ. [2] 47, a19. 
84 Genth: Ueber Korund, seine Umwandlungen,

sind. Sie sind mitunter fächerartig und strahlig; die krystallinischen Platten erreichen manchmal eine Grösse von drei Zoll. Thre Farbe ist gewöhnlich grünlich-gelb oder bräunlich-weiss; nach ihrer Behandlung mit Chlorwasserstoffsäure, wolche die geringe Menge des sie färbenden Eisenoxydhydrats entfernt, sind sie weiss mit einem sehr schwacher. Stich in's Meergrüne, selten bis grasgrün. Sie besitzen Perlmutterglanz, der sich zum Glasglanz hinneigt. -

Diese Krystalle oder krvstallinischen Platten von grösserem oder geringerem Durchmesser sind in inniger Berührung mit dem körnigen grauen oder bräunlich-weissen Korund, oder finden sich in dessen Masse vertheilt; mitunter findet eich zwischen ihnen und dem Korund ein Sănm von einem krystallisirten dunkelgrünen Chlorit. Schwarzer Tourmalin ist ein nicht ungewöhnlicher Begleiter, und, hauptsächlich da, wo der seltene Diaspor sich zeigt, finden sich dünne Krystalle von dunkelbläulichem, bräunlichem oder grünlichem Turmalin. Diese Varietät wurde von Sharpless (1. e.) und Dr. G. A. König untersucht (a).

b. Eine andere Varietät des Damourits besteht aus Aggregaten grau-weisser und gelblich-v eisser schuppiger Krystalle von etwa $1 / 16$ bis nicht über $1 / 4$ Zoll im Du-chmesser. Nach Behandlung mit Chlorwasserstoffaäure sind sie silbergrau.

Sie bilden einen Ueberzug auf Korund und manchmal die ganze Masse früher vorhanden gewesener Korundkrystalle, solche Aggregate sind wirkliche Pseudomorphosen nach Korund, von welchem gewöhnlich noch ein Kern übrig geblieben ist.

Ein Bruchstück eines schönen Krystalls von blauem Korund über 3 Zoll lang und etwa $2^{1 / 2}$ Zoll im Durchmesser mit einem Ueberzug von Damourit von $1 / 3$ bis $1 / 4$ Zoll Durchmesser findet sich in der Sammlung von Isaac Lea, welcher mir das Material für die Analyse (b1) gütigst mittheilte. Er und Coll. Jos. Willcox besitzen die reichsten Sammlungen von amerikanischen Korund- 
vorkommnissen und mehrere ausgezeichnete Exemplare dieser Art von Unionville. - Die Analyse (b2) wurde mit aus grauem Korund entstandenem Damourit angestellt.

c. Eine andre sehr schöne Varietät desselben Minerals bildet ebenfalls pseudomorphe Krystalle nach Korund. Das Material für meixe Analyse kam von einem Krystallfragment, das noch an zwei Seiten Pyramidenflächen zeigt. Ein Kern von grauem Korund ist noch vorhanden, von welchem die Schüppchen des weissen perlmutterglänzenden Damopnits ausstrahlen und ihm eine pseudofaserige Structur geben (c).

d. Die Schüppchen des Damourits werden mitunter so fein, dass sie sich nicht mehr mit blossem Ange unterscheiden lassen, und das Mineral wird dicht, manchmal kugelförmig, manchmal schieferig, ähnlich manchem Talkschiefer. Aggregate grosserer Schuppen von grünlichweisser Farbe und Perlnutterglanz sind mitunter in der Masse eingemengt. Eine Analyse der dichten kugelförmigen grünlich-weissen kryptokrystallinischen Varietät wurde von Dr. G. A. Koenig ausgeführt (d).

e. Eine weisse oder graulich-weisse Varietät von feinschuppiger, oft kryptokrvstallinischer. Structur, die mitunter schieferig ist, gewöhnlich aber pseudofaserig, die faserigen Aneinanderreihungen der Schüppchen von $1 / 3$ bis über sechs Zoll Länge, umhüllt häufig den körnigen grau-weissen Korund. Thr Glanz ist gewöhnlich schwach perlmutterartig, sich zum Seidenglanz neigend. Schuppen von weisrem oder grünlich-weissem Damourit sind durch die Masse vertheilt, manchmal in Schnüren, mitunter in solcher Menge, dass das Ganze eine körnig-schuppige Felsart bildet. Fine Analyse des pseudofaserigen, weissen Damourits worde von Dr. G. A. Koenig gemacht (e).

Auf der einen Seite und in der Regel am weitesten vom Korund entfernt, wird er nach und nach unrein grüu und in reinen Chlorit umgewandelt.

f. In inniger Berührung mit dem Korund tritt gewöhnlich noch eine weitere Varietät des Damourits auf, 
welche einen Saum zwischen ihm und der Varietät (e) bildet und zwischen $1 / 4$ und zwei Zoll breit ist. Sie ist kryptokrystallinisch und bestebt aus unendlich feinen Schüppchen, die in faseriger Structur rechtwinklig zum Korund angeordnet sind. Dieser Damourit hat viele Aehnlichkeit mit einigen Varietäten von Serpentin. Er hat eine gelblich-ölgrüne Farbe und ist entweder ohne Glanz oder besitzt Wachsglanz. - Es ist höchst merkwürdig, dass die dünnen Turmalinkryställchen, welche häufig in der weissen Varietät (e) auftreten und bis in den Chlorit sich fortsetzen (wovon weiter unten), in den vielen Stücken, welche ich untersuchte, niemals ihren Anfang in der ölgrünen Varietät nahmen.

Folgende Analysen wurden angestellt, (f 1) von einer körnigen Korund einschliessenden Masse von mir; (f2) das Mittel zweier gut übereinstimmender von Thos. M. Chatard gemachten Analysen eines sehr charakteristischen Stückes aus der Mitte zwischen Korund und der weissen Varietät (e).

g. Höchst interessante Pseudomorphosen von Damourit nach Korund treten in Laurens District, Südcarolina, wahrscheinlich im Glimmerschiefer (Damouritschiefer) auf. Ich habe oben erwähnt, dass die meisten Korundkrystalle dieses Fundorts einen Ueberzug eines glimmerartigen Minerals hatten, welches als Damourit bestimmt wurde. Die Pseudomorphosen zeigen die Form des Korunds, sind aber zusammengedrückt, als ob sie einen grossen Druck ausgehalten hätten. Viele enthalten noch einen Kern von unveründertem Korund, während andere vollkommen umgewandelt sind und aus einem Aggregat von kleinen gelblich-weissen Schuppen bestehen, welche durch Chlorwasserstoffsäure gereinigt, silberweiss werden. Meine Analyse derselben s. u. (g).

h. Diesem sehr ähnlich ist der Damourit, welcher auf der Culsagee-Grube ein Lager von Glimmerschiefer bildet, und unzählige, aber stets mehr oder weniger umgewandelte Korundkrystalle enthält; begleitende Mineralien sind der oben erwähnte Staurolit und einige schwarze 
Mineralien, wahrscheinlich Menaccanit u. s.w. Die Damouritblättchen sind etwas grösser, als die von Südcarolina, und gaben nach ihrer Reinigung durch Chlorwasserstoffsäure dem Dr. G. A. Koenig die unter (h) angegebenen Resultate.

i. Der Krystalle and Massen blauen Korundes einschliessende Damourit von Crowder's Mountain, Grafschaft Gaston, Nordcarolina, welcher ebenfalls aus der Zersetzung desselben hervorgeht, bildet gewöhnlich eisenschüssige Blättchen. Das durch Chlorwasserstoffsäure gereinigte Material wurde durch Thos. M. Chatard untersucht (i).

Folgendes sind die Resultate der Analysen der verschiedenen Varietäten :

\begin{tabular}{|c|c|c|c|c|c|c|}
\hline & $\mathbf{a}$ & (b 1) & $(b 2)$ & (c) & (d) & (e) \\
\hline Spec. Gew. & 2,851 & - & 2,843 & - & 2,857 & 2,832 \\
\hline $\mathrm{SiO}_{2}$ & $=43,03$ & 45,49 & 45,57 & 45,86 & 45,73 & 45,73 \\
\hline $\mathrm{Al}_{2} \mathrm{O}_{3}$ & $=39,06$ & - & 34,83 & 37,65 & 37,10 & 3630 \\
\hline $\mathrm{Fe}_{2} \mathrm{O}_{3}$ & $=1,48$ & 2,34 & 2,94 & 0,59 & 1,30 & 0,83 \\
\hline $\mathrm{MgO}$ & $=0,80$ & - & 0,83 & 0,55 & 0,34 & 0,54 \\
\hline $\mathrm{CaO}$ & $=\mathbf{S p u r}$ & - & 0,40 & 0,31 & Spux & 0,74 \\
\hline $\mathrm{Iin}_{2} \mathrm{O}$ & $=$ Spur & - & Spur & Spur & Spur & Spur \\
\hline $\mathrm{Na}_{2} \mathrm{O}$ & $=0,58$ & 0,32 & 0,87 & 0,80 & 0,88 & 0,58 \\
\hline $\mathrm{K}_{2} \mathrm{O}$ & $=10,05$ & 9,88 & 10,16 & 10,40 & 10,50 & 10,49 \\
\hline \multirow[t]{2}{*}{ Glühverlust } & $=\quad 0,40$ & 3,89 & 5,80 & 4,74 & 4,48 & 5,17 \\
\hline & 99,90 & & $\overline{00}, \overline{90}$ & 100,90 & 100,63 & 100,38 \\
\hline
\end{tabular}

\begin{tabular}{|c|c|c|c|c|c|c|}
\hline & & (f1) & (f2) & $(g)$ & (h) & (i) \\
\hline Spec. Gew. & $=$ & 2,779 & 2,760 & - & 2,867 & 2,860 \\
\hline $\mathrm{SiO}_{2}$ & $=$ & 46,98 & 46,60 & 45,71 & 45,62 & $48,51 \quad)$ \\
\hline $\mathrm{Al}_{2} \mathrm{O}_{3}$ & $=$ & 35,13 & 32,39 & 34,12 & 35,93 & 37,85 \\
\hline $\mathrm{Fe}_{2} \mathrm{O}_{3}$ & $=$ & 0,61 & 2,54 & 3,45 & 2,98 & 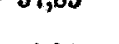 \\
\hline $\mathrm{MgO}$ & $=$ & 1,32 & 2,01 & 0,71 & 0,34 & 0,31 \\
\hline $\mathrm{CaO}$ & $=$ & 0,19 & Spur & 0,48 & Spur & 0,42 \\
\hline $\mathrm{Li}_{2} \mathrm{O}$ & $=$ & Spur & Spur & Spux & Sipur & Spur \\
\hline $\mathrm{Na}_{2} \mathrm{O}$ & $=$ & 0,76 & 0,54 & 0,49 & 0,71 & 1,04 \\
\hline $\mathrm{K}_{2} \mathrm{O}$ & $=$ & 10,74 & 10,39 & 10,36 & 9,40 & 11,35 \\
\hline \multirow[t]{2}{*}{ Glühverlust } & $=$ & 4,77 & 4,81 & 4,67 & 4,93 & $\left.7,73^{1}\right)$ \\
\hline & & 100,44 & 99,28 & 99,99 & 99,86 & 102,21 \\
\hline
\end{tabular}

Obgleich der Zweck vieler dieser Analysen nur die Bestimmung der Species im Auge hatte, so wurde dennoch

1) Mittel von drei Bestimmungen. 
stets das Material für dieselben mit grosser Sorgfalt ausgewählt. Trotzdem zeigten emige noch Spuren von Karund, wodurch der Gehalt an Kieselsäure oder Thonerde anscheinend etwas erhöht wird; die Mehrzahl derselben jedoch stimmt vollständig mit der angenommenen Formel, deren Sauerstoffver'ıältniss von $\mathrm{RO}: \mathrm{R}_{2} \mathrm{O}_{3}: \mathrm{Si} \mathrm{O}_{2}: \mathrm{H}_{2} \mathrm{O}$ $=1: 9: 12: 2$. Einige Varietäten enthalten einen Theil. der Thonerde durch Eisenoxyd ersetzt. - Nur der Damourit von Crowder's Mountain giebt, als übereinstimmendes Resultat dreier Bestimmungen, 3 Mol. Wasser.

\section{Ephesit-Lesleyit.}

J. L. Smith (l,c.) beschreibt in seinen Untersuchungen über Smirgel (emery) unter dem Namen Ephesit ein Mineral, welches Lamellenstructur zeigt und weissem Cyanit ähnlich sieht. Ich werde unten seine Analyse des Ephesits anführen, ausserdem eix,e von mir mit Material, welches mir derselbe gütigst zum Vergleich bei meinen Untersuchungen über Korund zusandte. Beide stimmen ziemlich gut überein, doch halte ieh die von $S$ mith für die bessere, da er eine grossere Quantität und sicher besseres Material zur Verfügung hatte. Der Zweck meiner Analyse war übrigens ein ganz anderer, nämlich der, zu untersuchen, ob die von ihm gefundene Thonerde vollständig zur Constitution des Minerals gehört, oder ob ein Theil derselben als Korund mechanisch beigemengt sei, welches Letztere unwiderleglich bewiesen wurde.

Ein ähnliches Mineral von Unionville, wurde von Isaak Lea (l. c.), der keine Gelegenheit gehabt hatte, den Ephesit kennen zu lemen, als Lesleyit beschrieben. Er beobachtete die Umwandlung des harten Korunds in weiche Mineralien, die er in Ermangelung von Analysen alle für identisch bielt: ein sehr $\mathrm{zu}$ entschuldigender Irrthum.

Von den dichten und faserigen Damouriten, die er hierher rechnete, habe ich bereits gesprochen, von den 
Margariten wird weiter unten die Rede sein, ich will jetzt nur die dem Ephesit analogen, von Lea zuerst beschriebenen und typischen Lesleyite in Betrachtung ziehen. Diese waren bereits Gegenstand der Untersuchungen von S. P. Sharpless ${ }^{1}$ ), J, L. Smith ${ }^{2}$ ) und G. J. Brush ${ }^{3}$ ). Es existiren drei verschiedene Varietäten:

a. Die erste ist aus einander laufend faserig, von grauweisser Farbe, oft durch Eisenoxydhydrat äusserlich gefärbt, mit zum Seidenglanz sich neigenden Perlmutterglanz. Ritzbar durch Flussspath und zu gleicher Zeit Quarz leicht ritzend. In Begleitung von schuppigem Damourit.

b. Die zweite Varietät ist der ersten sehr ähnlich, jedoch mehr eisenschüssig und weniger rein. Damourit und Pattersonit treten als Begleiter auf. Er enthält kleine Höhlungen durch seine ganze Masse und hat eine röthliche Farbe.

c. Die dritte Varietät enthält häufig ein chloritisches Mineral beigemengt. Der Lesleyit selbst ist feinfaserig, stänglig, manchmal divergirend, von graulich-grünlich- und bräunlich-weisser Farbe, sein Glänz zwischen Seiden- und Glasglanz. Leicht durch ein Messer ritzbar, aber härter als Apatit; einzelne Theile ritzen Quarz.

Thomas M. Chatard und ich analysirten die Varietät a, Dr. König und ich die Varietäten b und c; zur Vergleichung gebe ich die Analysen von Sharpless und C. W. Roepper, unter Sharpless Leitung angestellt. -

1) S. P. Sharpless, Sill. Jouru. [2] 47, 319.

3) J. T. Smith, Sill. Journ. [2] 48, 254.

5) G. J. Brush, Appendix, 5th edition of Dana's Mineralogy, New York 1872. 
90 Genth: Ueber Komnd, seine Umwandlungen,

Ephesit.

\begin{tabular}{|c|c|c|}
\hline & J.L.Smith & Genth \\
\hline $\mathrm{SiO}_{3}$ & $=80,70$ & 31,94 \\
\hline $\mathrm{Al}_{2} \mathrm{O}_{3}$ & $=55,67$ & 55,55 \\
\hline $\mathrm{Fe}_{2} \mathrm{O}_{3}$ & $=$ & 1,04 \\
\hline $\mathrm{MgC}$ (Spur $\mathrm{MnO})$ & - & Spur \\
\hline $\mathrm{CaO}$ & 2,55 & 3,82 \\
\hline $\mathrm{Li}_{2} \mathrm{O}$ & $=$ & Spur \\
\hline $\mathrm{Na}_{2} \mathrm{O}$ & 5,52 & 3,27 \\
\hline $\mathrm{K}_{2} \mathrm{O}$ & $=1,10$ & 1,68 \\
\hline \multirow[t]{2}{*}{ Glühverlust } & $=4,91$ & 5,12 \\
\hline & 00,45 & 01,72 \\
\hline
\end{tabular}

Beim Schmelzen mit Calciumcarbonat und Ammoniumchlorid blieben 10,26 p.C. Korund zurück.

Es war mir nicht möglich, aus obiger Analyse die Zusammensetzung des Gemenges zu berechnen, und diess wird unmöglich sein, so lange wir kein Mittel besitzen, den beigemengten Korund genau zu bestimmen.

Lesleyit.

a. Weiss

b. Röthlich

\begin{tabular}{|c|c|c|c|c|c|c|}
\hline & & & & \\
\hline & Genth & Chatard & Sharpless & Genth & Kounig & Roepper \\
\hline Spec. Gew. & $=-$ & 3,200 & 3,208 & - & 3,059 & 2,870 \\
\hline $\mathrm{SiO}_{2}$ & $=32,32$ & 32,32 & 33,59 & 31,96 & 31,90 & 47,00 \\
\hline $\mathrm{Al}_{2} \mathrm{O}_{3}$ & $=56,43$ & 55,23 & 55,41 & \multirow{2}{*}{56,85} & 54,09 & 33,27 \\
\hline $\mathrm{Fe}_{2} \mathrm{O}_{3}$ & $=0,29$ & -- & - & & 0,51 & 2,84 \\
\hline $\mathrm{MgO}$ & $=0,38$ & \multirow{2}{*}{0,73} & - & \multirow{2}{*}{$\begin{array}{l}0,13 \\
0,13\end{array}$} & 0,34 & - \\
\hline $\mathrm{CaO}$ & $=0,32$ & & - & & - & $\ldots$ \\
\hline $\operatorname{Li}_{2} \mathrm{O}$ & \multicolumn{2}{|c|}{$=$ Geringe Spuren } & - & \multicolumn{2}{|c|}{ Geringe Spuren } & - \\
\hline $\mathrm{Na}_{2} \mathrm{O}$ & $=0,32$ & 0,64 & - & 0,35 & 1,01 & - \\
\hline $\mathrm{K}_{2} \mathrm{O}$ & $=7,31$ & 7,82 & 7,43 & 7,83 & 8,71 & 9,97 \\
\hline Glühverlust & $=4,01$ & 3,86 & 4,30 & 4,09 & 4,20 & 6,71 \\
\hline & 101,38 & 100,60 & 100,73 & 101,34 & 100,76 & 99,79 \\
\hline
\end{tabular}

Beim Schmelzen mit Calciumcarbonat und Arnmoniumchlorid blieben bei a $-21,40$ p.C., bei b, 17,78 p.C. zurück.

Die Analyse der röthlichen Varietät dureh Roepper enthält angenscheinlich etwa 15 p.C. Korund in der gefundenen Kieselsäure. 
S.P.Sharpless bemerkt, dass beide Varietäten durch die Wirkung alkalischer Wässer auf Korund entstanden seien und dem Pinit näher ständen, als irgend einem andern Mineral; G. J. Brush, dass Ephesit und Lesleyit Gemenge von Korund seien, wahrscheinlich mit Diaspor, und einem Glimmer, ähnlich dem, an der Lesleyit-Localität vorkommenden Damourit, und dass das blättrige weiche Material Damourit sei, oder ein dieser Species nahe stehender wasserhaltiger Glimmer.

Ich hatte bereits vor dem Erscheinen von Brush Appendix die Gegenwart von freiem Korund im Lesleyit aufgefunden und kann jetzt den grösseren Theil seiner Bemerkungen bestätigen.

Eine Beimischung von Diaspor ist nicht vorhanden, wenn wir aber aus dem gefundenen Kali die Procentgehalte für einen dem weissen Lesleyit ähnlichsten Damourit (e) berechneu, so erhalten wir:

$$
\begin{aligned}
& \left.\begin{array}{l}
\mathrm{SiO}_{2}=31,87 \\
\mathrm{Al}_{2} \mathrm{O}_{3}=25,30 \\
\mathrm{Na}_{2} \mathrm{O}=0,40 \\
\mathrm{~K}_{2} \mathrm{O}=7,31 \\
\mathrm{H}_{2} \mathrm{O}=\mathbf{3 , 6 0}
\end{array}\right\}=68,48 \text { Damourit } \\
& \text { 30,00 Korund } \\
& 1,52 \text {. Silicate u. s. w. } \\
& 100,00
\end{aligned}
$$

Die Analyse von Shaxpless giebt etwa 69 p.C. Damourit und naheżu die nämliche Quantität beigemengten Korund.

Die Berechnung der Analysen der röthlichen Varietät giebt weniger befriedigende Resultate, ohne Zweifel wegen der grösseren Unreinheit des Minerals; doch entspricht sie einem Gemenge von etwa 70 p.C. Damourit, 27 p.C. Korund und 3 p.C. von andern Beimengungen.

Die dritte Varietät (c) des Lesleyits zeigt einen ganz verschiedenen Charakter. Die Analysen gaben folgende Zusammensetzung : 
92 Genth: Ueber Korund, seine Umwandlungen,

\begin{tabular}{|c|c|c|c|}
\hline & & Genth & Koenig \\
\hline Spec. Gew. & $=$ & $-\infty$ & $3,157^{\circ}$ \\
\hline $\mathrm{SiO}_{2}$ & $=$ & 35,68 & $34 ; 80$ \\
\hline $\mathrm{Al}_{2} \mathrm{O}_{3}$ & $=$ & 60,29 & 59,77 \\
\hline $\mathrm{Fe}_{2} \mathrm{O}_{3}$ & $=$ & 0,72 & 0,73 \\
\hline $\mathrm{MgO}$ & $=$ & 0,29 & - \\
\hline $\mathrm{Li}_{2} \mathrm{O}$ & $=$ & GeringsteSpur & - \\
\hline $\mathrm{Na}_{z} \mathrm{O}$ & $=$ & 0,41 & nicht bestimmt \\
\hline $\mathrm{K}_{2} \mathrm{O}$ & $\Rightarrow$ & 0,96 & ", \\
\hline Glührerlust & $=$ & 1,78 & 2,05 \\
\hline Korund & $=$ & - & 2,20 \\
\hline & & 100,13 & 99,55 \\
\hline
\end{tabular}

Durch Aufschliessen mit Calciumcarbonat und Ammoniumchlorid erhielt ich 11,08 p.C. Korund; die von Dr. Koenig gefundenen 2,20 p.C. sind beim Aufșchliessen mit Natriumearbonat übrig geblieben.

Das Sauerstoffverhältniss von $\mathrm{RO}: \mathrm{R}_{2} \mathrm{O}_{3}: \mathrm{SiO}_{2}: \mathrm{H}_{2} \mathrm{O}$ in diesen Analysen ist wie folgt:

Genth . . . . $0,39: 28,32: 19,03: 1,58=1: 72,6: 48,8: 4$

Koenig (argenommen 0,39) : 28,07:18,56:2,05=1:72 :47,6:5,3

Hieraus geht hervor, dass das Sauerstoffverhältniss von $\mathrm{R}_{2} \mathrm{O}_{3}: \mathrm{SiO}_{2}=3: 2$ ist oder genan das von Fibrolit. $\mathrm{Ob}-$ gleich es sehr wahrscheinlich ist, dass diese Varietät, sbenso wie die beiden andern ursprünglich aus der Umwandlung von Korund in Fibrolit entstanden ist, so ist der letztere in den beiden ersten Varietäten doch fast vollständig, in der letzten bereits zam Theil verschwunden. Der Versuch, aus den geringen Quantitäten von Kali, Natron und Magnesia die wahrscheinlichen Beimengungen zu berechnen, blieb ohne Erfolg.

Die gefundenen 11,08 p.C. Korund, machen eine Beimengung von 15 bis 16 p.C. wahrscheinlich.

\section{Paragonit.}

Ein höchst interessantes Vorkommen des Korunds ist das am Ochsenkopf bei Schwarzenberg in Sachsen. Er findet sich in körnigen Massen oder isolirten Körnchen von blaugrauer Farbe in einem schieferigen Gestein von bräuniich aschgrauer Farbe. Er wird von kleinen Blättchen dunkelgrünen Chloritoids, und einer höchst geringen Quantität eines blättrigen weissen glänzenden Minerals begleitet, welches wahrscheinlich Diaspor ist. Das schief- 
rige Muttergestein beseht aus sehr feinen weissen und bräunlich-weissen Schüppcheri, und das ganze Aussehen ist so so ähnlich einigen aus der Umwandlung des $\mathrm{Ko}$ runds hervorgegangenen Varietäten des Damourits, dass ich eine chemische Untersuchung für sehr wunschenswerth erachtete. Das Material für dieselbe wurde mit grosser Sorgfidt ausgesucht; und ergab folgende Resultate:

\begin{tabular}{|c|c|}
\hline $\mathrm{SiO}_{2}$ & $=43,70$ \\
\hline $\mathrm{TiO}_{2}$ & $=3,50$ \\
\hline $\mathrm{Al}_{2} \mathrm{O}_{3}$ & $=39,60$ \\
\hline $\mathrm{Fe}_{2} \mathrm{O}_{3}$ & $=0,66$ \\
\hline $\mathrm{MgO}$ & $=$ Spur \\
\hline $\mathrm{Ca}_{2} \mathrm{O}$ & $=0,56$ \\
\hline $\mathrm{Li}_{2} \mathrm{O}$ & $=$ Spur \\
\hline $\mathrm{Na}_{2} \mathrm{O}$ & $=6,52$ \\
\hline $\mathrm{K}_{2} \mathrm{O}$ & $=0,03$ \\
\hline Glühverlust & $=4,83$ \\
\hline
\end{tabular}

Da sich mit einer guten Loupe kein Rutil nachweisen liess, so war das Auffinden von Titansäure überraschend. Es wurde deshalb ein Theil des Schiefers zerdrückt, ohne ihn zu zerreiben, und die leichteren Theilchen durch Schlämmen von den schwereren getrennt. Letztere zeigten nun unter dem Mikroskop zabllose Körnchen gelblich-braunen Rutils.

Nach Abzug des mechanisch beigemengten Rutils zeigt dieser Schiefer die Zusammensetzung des Paragonits, und zur Vergleichung gebe ich eine Analyse des vom St. Gotthard von Rammelsberg und des von Pregatten in Tyrol (Pregattit-) von Oellacher:

\begin{tabular}{|c|c|c|c|c|c|c|c|}
\hline $\mathrm{Si} \mathrm{O}_{2}$ & $\begin{array}{l}\text { St.Gotthar } \\
=46,81\end{array}$ & $\begin{array}{c}\text { Pd Pregatt } \\
44,6 \check{5}\end{array}$ & en Ochsenk & & acer: & & 24,07 \\
\hline $\mathrm{Al}_{2} \mathrm{O}_{3}$ & $=40,06$ & 40,41 & 40,91 & , & \# & 19,06 & \\
\hline $\mathrm{Cr}_{2} \mathrm{O}_{3}$ & $=-$ & 0,10 & - & , & " & & $=19,26$ \\
\hline $\mathrm{Fe}_{2} \mathrm{O}_{3}$ & $=$ Spur & $F_{\odot O O}=0,84$. & $\mathrm{Fe}_{2} \mathrm{O}_{3}=0,68$ & & " & $0,20\}$ & \\
\hline $\mathrm{MgO}$ & $=0,65$ & 0,37 & Spur & & & & \\
\hline $\mathrm{CaO}$ & $=1,26$ & 0,52 & 0,58 & " & $"$ & $0,17)$ & \\
\hline $\mathrm{Li}_{2} \mathrm{O}$ & $=-$ & - & Spur & & & & 2.07 \\
\hline $\mathrm{Na}_{2} \mathrm{O}$ & $=6,40$ & 7,06 & 6,74 & ” & $"$ & 1,74 & \\
\hline $\mathrm{K}_{2} \mathrm{O}$ & $=$ Spur & 1,71 & 0,96 & $"$ & $"$ & $0,16)$ & \\
\hline Glühverlust & 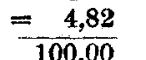 & $\begin{array}{r}5,0^{\prime} \\
10070\end{array}$ & $\begin{array}{r}4,99 \\
100,00\end{array}$ & ", & $"$ & & 4,44 \\
\hline
\end{tabular}


94 Genth: Ueber Korund, seine Umwandlungen,

Das Sauerstoffverhältniss von $\mathrm{RO}: \mathrm{R}_{2} \mathrm{O}_{3}: \mathrm{SiO}_{2}: \mathrm{H}_{2} \mathrm{O}$ ist $=1: 9,3: 11,6: 2,1$, oder sehr nahe wie $1: 9: 12: 2$, wie das vom Damourit. Paragonit ist ein SodaDamourit.

Das von $J \circ h n^{1}$ ) untersuchte Mineral vom Ochsenkopf gehört nicht hierher.

Ich habe oben eine eigenthümliche Felsart erwähnt, welche in der Nachbarschaft von Media, Grafschaft Delaware in Pennsylvanien, und bei der Culsagee-Grube in N. C. vorkommt und aus schiefrigem Fibrolit besteht mit Krystallen von Cyanit und Stanrolit-, und bemerkte, dass das Ganze lebhaft an die Paragonit-Schiefer vom St. Gotthardt erinnere. - Nachdem ich die Umwandlung des Korunds und Fibrolits in Damourit bewiesen habe, sowie die des Korunds vom Oehsenkopf in Damourit, wirft sich die Frage auf: sind nicht alle Paragonit-Schiefer vom St. Gotthardt und andrer Fundorte das Resultat der Umwandlung von Korund oder Fibrolit?

\section{Euphyllit.}

Euphyllit mit Turmalin und Zoisit ist ein seltner Begleiter des Korunds von Unionville. Er entsteht ohne Zweifel wie die andern aus der Umwandlung des Korunds. $\mathrm{Da}$ ich nicht hinreichend Material für eine neue Analyse hatte und die Resultate der alten von Smith und Brush keine Zweifel zuliess, wurde keine weitere Untersuchung damit angestellt.

Ein weisses glimmerartiges Mineral, welches mit Korund und Albit in der Nähe von Unionville vorkommt und dem Muscovit täuschend ähnlich sieht, gab Dr. Koenig otwa 42 p.C. Kieselsäure. Es ist wahrscheinlich identiseh mit dem vor Sharpless ${ }^{2}$ ) analysirten, und denen mit ähnlichem Kieselsäuregehalt von Kleinasien und Nicaria, die J. L. Smith untersuchte.

1) Dana's Mineralogy, 5th. edition, 482 .

2) Dana's Mineralogy, 5th. edition, 488 und 489 . 


\section{Jefferisit.}

Jefferisit, zuerst von G. J. Brush als eigenthümlich unterschieden, findet sich häufig als Product der Umwandlung von Chlorit, also indirect der des Korunds. Zu Unionville findet er sich selten in unregelmässigen Platten und Krystallen von braungelber Farbe. Er bläht sich auf wie der von Westchester.

Auf der Culsagee-Grube kommt er häufiger vor, der Chlorit zeigt oft eine beginnende Umwandlung durch eine Farbenveränderung der Blätter, welche braun oder gelblich-braun werden. Wenn die Umwandlung vollständig ist, erscheint er in Platten von einer gelblichbraunen Farbe, welche sich weder durch ihre physikalischen Eigenschaften noch durch die Art ihres Aufblähens von dem der ursprünglichen Localität unterscheiden lassen. Eine andere Varietät von der Culsagee-Grube mit einer beträchtlichen Beimengung von Korundfragmenten, kommt in feinen grünlich-bräunlich-gelben Schuppen vor, die nicht über $1 / 8$ im Durchmesser haben. Es wurden analysirt:

a. der breitblättrige von der Culsagee-Grube von Dr. Koenig (a1) und Thomas M. Chatard (a2).

b. der grünlich-bräunlich-gelbe in feinen Sohuppen, von Thomas M. Chatard (b).

c. und zur Vergleichung, der breitblättrige von Westchester, Pa., von Dr. Koenig (c1) und Thomas M. Chatard (c2); ich füge ausserdem die Analyse desselben von G. J. Brush bei (c3).

\begin{tabular}{|c|c|c|c|c|c|c|}
\hline \multirow{7}{*}{$\begin{array}{l}\mathrm{SiO}_{2} \\
\mathrm{Al}_{2} \mathrm{O}_{3} \\
\mathrm{Fe}_{2} \mathrm{O}_{3} \\
\mathrm{FeO} \mathrm{O} \\
\mathrm{NiO}\end{array}$} & \multicolumn{3}{|c|}{ Culsagee } & \multicolumn{3}{|c|}{ Westchester } \\
\hline & (a1) & (a2) & (b) & (c1) & (c) & $(03)$ \\
\hline & $=33,93$ & 33,77 & 34,00 & $\mathbf{3 3}, \mathbf{3 5}$ & $\mathbf{3 4 , 4 0}$ & $\mathbf{3 7 , 1 0}$ \\
\hline & $=17,38$ & 17,5 & 20,36 & 17,78 & 16,63 & 17,57 \\
\hline & $=5,42$ & 5,61 & 4,91 & 7,32 & 8,00 & 10,54 \\
\hline & $=0,50$ & $\left.0,50^{x}\right)$ & 0 & 2,11 & $\left.2,11^{1}\right)$ & 1,26 \\
\hline & $=0,95$ & nirht bestimmt & 0,57 & - & - & - \\
\hline $\mathrm{MgO}$ & $=20,43$ & 22,48 & 21,71 & 19,26 & 19,30 & 19,65 \\
\hline $\mathrm{CaO}$ & - & - & - & \multirow{2}{*}{\multicolumn{2}{|c|}{ nicht bestimmt }} & 0,56 \\
\hline $\mathrm{Na}_{2} \mathrm{O}$ & $=$ & - & - & & & Spur \\
\hline $\mathbf{A}_{\mathbf{2}} \mathbf{U}$, & $=$ & - & - & & & 0,43 \\
\hline rerlust & $=19,17$ & 20,30 & 18,50 & 19,87 & 19,08 & 13,76 \\
\hline & 100,18 & 100,28 & 100,47 & 99,69 & 99,47 & $100, \overline{87}$ \\
\hline
\end{tabular}

1) Chatard bestimmte nur das Eisenoxyd, und nahm Dr. Koenig's Resultat für's Eisenoxydul. 
96 Genth: Ueber Korund, seine Umwandlungen, sind in:

Die Sauerstoffverhältnisse von $\mathrm{RO}: \mathrm{R}_{2} \mathrm{O}_{3}: \mathrm{SiO}_{2}: \mathrm{H}_{2} \mathrm{O}$

$$
\begin{aligned}
& \text { a1 }=2,94: 3: 5,59: 5,26 \\
& \text { a } 2=2,77: 3: 5,48: 5,49 \\
& \text { b }=2,43: 3: 5,00: 4,50 \\
& \text { c1 } 1=2,33: 3: 5,09: 5,05 \\
& \text { c2 } 2,2,42: 3: 5,42: 5,00 \\
& \text { c } 3=2,21: 3: 5,23: 3,23
\end{aligned}
$$

Die grossen Unterschiede in diesen Analysen erlauben kaum, eine Formel für das Mineral zu construiren. Die Analysen a 1 und a 2 geben nahezu $6 \mathrm{RO}+2 \mathrm{R}_{2} \mathrm{O}_{3}+5 \mathrm{SiO}_{2}$ $+10 \mathrm{H}_{2} \mathrm{O} ; \mathrm{b}$, c1 und c2 nahezu $5 \mathrm{RO}+2 \mathrm{R}_{2} \mathrm{O}_{3}+5 \mathrm{SiO}_{2}$ $+10 \mathrm{H}_{2} \mathrm{O}$.

(Die grösste und mir unerklärliche Differenz besteht zwischen den Resultaten von Prof. Brush and Dr. Koenig und Th. M. Chatard, namentlich in den Quantitäten der Kieselsäure und des Wassers in Westchester Jefferisit. Dr. Koenig's Analyse wurde mit dem fein gepulverten and der trocknen Luft des Zimmers ausgesetzten Mineral angestellt; Chatard's Material kam von einem andern Stück, er trocknete das fein gepulverte Mineral vier Tage lang im Vacuum über Schwefelsäure; auf dieselbe Weise wurde der J, von Culsagee behandelt).

\section{Chlorit.}

In der geologischen Skizze habe ich erwähnt, dass chloritische Felsarten an fast allen Orten vorkommen, wo Korund in grossen Massen oder Lagern gefunden wird. Es bleibt nun noch übrig, eine Anzahl eigenthümlicher Verhältnisse zu untersuchen, unter denen Korund und Chlorit zusammen auftreten, um daraus Schlüsse auf das ganze Vorkommen ziehen zu können.

a. Bei Unionville im Schacht an dem Weg nach Kennett Square findet sich Chlorit in auffallender Weise; er ist oft innig mit Spinell gemengt und enthält, wie ich 
oben gezeigt habe, eime beträchtliche Beimengung von Korund.

b. Im grossen Korundlager bei Unionville tritt Chlorit unter verschiedenen Verhältnissen auf. Manchmal bilden kleine dunkelgrüne Krystalìe einen Raum zwischen Korund und blättrigem Damourit, oder der Korund ist in Schnüren oder Blättchen durch die Korundmasse vertheilt, oder er erscheint in grossen abgerundeten Massen, die aus Aggregaten feiner Schuppen bestehen, die sich schieferig un einen Centralpunkt abgelagert haben, und häufig im Innern noch einen Kern von körnigem Korund zeigen. Der Cblorit ist von einer unreinen ölgrünen Farbe, aber häufig unter dem Einflass der Atmosphärilien in röthliche oder gelblich-braune Schuppen oder selbst zu einem eisenschüssigen Thon umgewandelt, der dann in seinem Innern noch Reste unzersetzten Korunds enthält.

c. Fine audere Varietät entsteht, wie bereits oben angedeutet, aus der Umwandlung von Damonrit nnd Turmalin, also indirect aus der des Korunds. Die pseudofasrige Varietät des Damourits (e) nimmt nach und nach einen grünlichen Ton an durch eine höchst geringe Beimengung von Chlorit, dessen Quantität raseh zunimm $\hat{t}$ und bald in einen reinen feinschuppig körnigen hell oliven. grünen Chlorit umgewandelt wird. Die dünnen Turmalinkryställchen setzen aus dem Damourit in den Chlorit fort, jedoch nur für eine kurze Strecke, da auch sie bald vollständig mit Beibehaltung ihrer Form in schuppig-körnigen Chlorit umgewandelt werden; die pseudomorphen Krystalle bilden die Fortsetzung der Turmalinkrystalle, und sind wie dieser in dem schuppig-körnigen Chlorit eingebettet. Dies ist ein höchst interessantes Vorkommen and ganz ähnlich dem von G. Rose (I. c.) beschriebenen, nach welchem zu Kassoibrod im Ural, in den mit dem Korund vorkommenden Chloritschiefern, Pseudomorphosen von Chlorit nach Turmalin eingeschlossen sind

Thomas M. Chatard machte zwei Analysen dieses Chlorits von Unionyille (c1 und c2), eine andere, die ich Journal f. prakt. Chemie [2] Bd. 8. 
zum Vergleich mittheile, wurde vor Kurzem von A. R. Leeds publicirt (c3).

d. Die Culsagee-Grube bei Franklin, N. C., hat eine grosse Anzahl von sehr interessanten Stücken geliefert.

Einige, welche Aggregate von dunkelgrünem blättrigem Chlorit sind, zeigen noch deutlich die Contouren der hexagonalen Form des Korunds, und zeigen in der Regel noch einen Kern desselben; andere sind weniger regelmässig in ihrer Form und scheinen Fragmente von massivem Korund gewesen zu sein, ehe sie umgewandelt wurden. Die darin auftretenden Korundkerne sind oft frei von Beimengungen, häufig aber sind solche von Chlorit, oft in grossen Quantitäten. Fin häufiges Vorkommen ist das der Umwandlung des Korunds in Spinell, welcher dann ebenfalls wieder zu Chlorit verändert wird.

$\mathrm{Ob}$ nun der Chlorit aus dem einen oder andern $\mathrm{Ma-}$ terial entstanden ist, so zeigt er häufig an der Berührungstelle mit dem noch unzersetzten Kern eine feinschuppige, pseudofaserige Structur und nimmt erst in einer grösseren Entfernung blättriges Gefüge an; doch finden sich auch häufig die grossblättrigen Chlorite in directer Berührung mit Korund und Spinell, und einige der grössten Platten, von 3 bis 4 Zoll im Durchmesser, enthalten eine beträchtliche Menge Korund durch die ganze Masse vertheilt. Nicht aller Korund, der im Chlorit vorkommt, muss indessen als ein Rest, der der Zersetzung entgangen ist, betrachtet werden. Es finden sich nicht selten vollkommen ausgebildete und glänzende Korundkrystalle, welche gebildet zu sein scheinen, nachdem der grösste Theil der Korundmasse in Chlorit umgewandelt war, als ob ein Ueberschuss von Thonerde vorhanden gewesen wäre, der nicht die nöthige Quantität von Kieselsăure und Basen vorfand, um Chlorit zu bilden, und deshalb wieder als Korund auskrystallisirte.

Folgende Analysen von Chlorit von der CulsageeGrube wurden gemacht: dunkelgrüner breitblättriger (d 1$)$ von mir selbst, (d2) und (d3) ron Thomas M. Cha- 
tard; feinschuppig psendofaserig, von Korund divergirend, von mir selbst - (d4) und (d5).

e. Aehnliche Kerne unveränderten Korunds finden sich im Chlorit von Shooting Creek, Grafschaft Clay und andern Localitäten in Nordcarolina.

Feinschuppig-körniger.Chlorit von Unionville, Pa.

\begin{tabular}{|c|c|c|c|c|}
\hline \multirow{9}{*}{$\begin{array}{l}\mathrm{SiO}_{2} \\
\mathrm{Al}_{2} \mathrm{O}_{3} \\
\mathrm{Fe}_{2} \mathrm{O}_{3} \\
\mathrm{FeO} \\
\mathrm{Mg}_{\mathrm{g}} \mathrm{O} \\
\mathrm{Li}_{2} \mathrm{O} \\
\mathrm{Nm}_{2} \mathrm{O} \\
\text { Clührerlust }\end{array}$} & \multicolumn{2}{|r|}{ (c 1) } & (c2) & (c3) \\
\hline & $=$ & 29,43 & 29,59 & 30,62 \\
\hline & $=$ & 22,08 & 22,18 & 21,79 \\
\hline & $=$ & 1,41 & 1,83 & 0,42 \\
\hline & $=$ & 5,64 & 5,77 & 5,01 \\
\hline & $=$ & 28,46 & 28,54 & 29,68 \\
\hline & $=$ & \multirow{2}{*}{\multicolumn{2}{|c|}{ nicht bestimmt }} & 0,11 \\
\hline & & & & 0,11 \\
\hline & $=$ & 12,40 & 12,40 & 12,26 \\
\hline & & 99,42 & 99,81 & 89,98 \\
\hline
\end{tabular}

Chloritvarietäten von der Culsagee-Grube.

\begin{tabular}{|c|c|c|c|c|c|}
\hline & $(\mathrm{d} 1)$ & (d2) & (d 3) & (d 1) & (d 5) \\
\hline $\mathrm{SiO}_{2}$ & $=27,56$ & 27,28 & 27,17 & 29,48 & 29,59 \\
\hline $\mathrm{Al}_{2} \mathrm{O}_{3}$ & $=22,75$ & 22,11 & 22,35 & 22,22 & nicht bestimmt \\
\hline $\mathrm{Fe}_{2} \mathrm{O}_{3}$ & $=2,56$ & 2,50 & 2,71 & 0,70 & 0,64 \\
\hline $\mathrm{FeO}$ & $=5,43$ & 8,49 & 5,48 & 5,80 & nicht bestimmt \\
\hline $\left.\begin{array}{l}(\mathrm{NiCo}) 0 \\
\mathrm{MnO}\end{array}\right\}$ & $=0,90$ & 0,41 & 0,26 & $\begin{array}{l}0,11 \\
0,17\end{array}$ & $"$ \\
\hline $\mathrm{MgO}$ & $=28,47$ & 28,34 & 27,79 & 30,99 & 30,88 \\
\hline Glühreriust & $=13,80$ & $14 ; 50$ & 14,36 & 11,63 & 11,56 \\
\hline & 100,87 & 100,42 & 100,01 & 100,60 & \\
\hline
\end{tabular}

Besondere Anfmerksamkeit wurde der Bestimmung der Oxydationsstufen, in welcher das Eisen existirt, geschenkt; das Eisenoxyd rührt nicht, wie Leeds vermuthet, von einer oberflächlichen Oxydation des Chlorits ber; sondorn ist ein wesentlicher Bestandtheil der Chlorite, und macht einen wesentlichen Unterschied in den Verhăltnissen zwischen den Oxyden and Sesquioxyden. 
100 Genth: Ueber: Korund, seine Umwandlungen,

Das Sanerstoffverhältniss von $\mathrm{RO}: \mathrm{R}_{2} \mathrm{O}_{3}: \mathrm{SiO}_{2}: \mathrm{H}_{2} \mathrm{O}$ in obigen Analysen ist: in

$$
\begin{aligned}
& \mathrm{c} 1=3,50: 3: 4,40: 3,09 \\
& \mathrm{c} 2=3,50: 3: 4,40: 3,08 \\
& \left.\mathrm{c} 3^{2}\right)=3,83: 3: 4,78: 3,19 \\
& \mathrm{~d} 1=3,66: 3: 4,20: 3,55 \\
& \mathrm{~d} 2=3,43: 3: 3,95: 3,50 \\
& \mathrm{~d} 3=3,30: 3: 3,87: 3,41 \\
& \text { d } 4=3,84: 3,4,65: 2,93
\end{aligned}
$$

Dies kommt am nächsten den Verhältniss $7: 6: 8: 6$ und correspondirt am besten mit der von Rammelsberg. vorgeschlagenen Formel: $4 \mathrm{RO}, \mathrm{SiO}_{2}+3 \mathrm{RO}, 2 \mathrm{R}_{2} \mathrm{O}_{3}$ $+6 \mathrm{H}_{2} \mathrm{O}$.

Alle diese Chlorite gehören zu G. Rose's Ripidolit, der von Dana jetzt als Prochlorit unterschieden wird.

Ausser Jefferisit scheinen noch einige andere und neue Producte der Veränderung des Chlorits zu existiren, die ich unter $\mathrm{Nr} .22$ und 23 beschrieben habe.

\section{Kerrit (ein neues Mineral).}

Name nach Prof. W. C. Kerr, Staatsgeologen von Nordcarolina.

Er besteht aus einem Aggregat unzähliger Schüppchen, welche unter dem Mikroskop keine bestimmbare Form zeigen. Sie sind sehr weich. - Spec. Gew. $=2,303$ (Chatard). Farbe blass grunlich-gelb mit einem Stich ins Bräunliche. Perlmutterglanz.

Beim Erhitzen bläht er sich auf, doch nicht wie Jefferisit; v. d. L. schmilzt er zu weisser Emaille. Chlorwasserstoffsäure zersetzt ihn beim Erhitzen leicht unter Abscheidung der Kieselsäure in perimutterglänzenden Schuppen. Kein Korund fand sich in den untersuchten Stuicken, dagegen blättriger Chlorit.

1) Deı Druckfehler in Leed's Sauerstofiverhältniss habe ich corrigirt und dasselbe in Uebereinstimmung mit meinen Ansichten in Betreff der Oxydationsstufeu des Fisens gebracht. - 
Er wurde von Thos. M. Chatard analysirt, der das unter dem Mikroskop als homogen erkannte Material folgendermassen zusammengesetzt fand:

\begin{tabular}{|c|c|c|c|c|c|c|c|}
\hline \multirow{3}{*}{$\begin{array}{l}\mathrm{SiO}_{2} \\
\mathrm{Al}_{2} \mathrm{O}_{3}\end{array}$} & \multicolumn{5}{|c|}{ Mittel } & \multirow{2}{*}{\multicolumn{2}{|c|}{20,42}} \\
\hline & $=38,31$ & 38,26 & 38,29 & \multicolumn{2}{|c|}{ enthält Sauerstoff } & & \\
\hline & $=11,41$ & 11,42 & 11,41 & $"$ & $"$ & $5,32\}$ & 50 \\
\hline $\mathrm{Fe}_{2} \mathrm{O}_{3}$ & $=1,93$ & 1,97 & 1,85 & $"$ & " & 0,59 & 0,91 \\
\hline $\mathrm{FeO}$ & 0,32 & 0,32 & 0,32 & $"$ & $"$ & $0,07)$ & \\
\hline$(\mathrm{NiCl}) \mathrm{O}$ & $=0,29$ & 0,22 & 0,25 & 》 & $"$ & 0,05 & $=10,66$ \\
\hline $\mathrm{MgO}$ & $\simeq 26,30$ & 26,50 & 26,40 & " & * & $10,46)$ & \\
\hline Giülirerlust & $=21,22$ & 21,28 & 21,25 & " & ” & & 18,89 \\
\hline & 99,78 & 99,97 & 99,87 & & & & \\
\hline
\end{tabular}

Das Sauerstoffverhältniss der Durchschnittsanalyse für $\mathrm{RO}: \mathrm{R}_{2} \mathrm{O}_{3}: \mathrm{SiO}_{2}: \mathrm{H}_{2} \mathrm{O}=5,4: 3: 10,3: 9,5$ oder ziemlich nabe $=6: 3: 10: 10$, welebes durch $2\left(3 \mathrm{RO}, 2 \mathrm{SiO}_{2}\right)+\left(\mathrm{R}_{2} \mathrm{O}_{3}, \mathrm{SiO}_{2}\right)$ $+10 \mathrm{H}_{2} \mathrm{O}$ ausgedrückt werden kann.

23. Maconit (ein neues Mineral).

Dies ist ein anderes schuppiges Mineral, welches grosse Aehnlichkeit mit einem feinschuppigen Jefferisit hat. Etwas härter als Kerrit, die Schuppen aber ebenso unregelmässig unter dem Mikroskop. Spec. Gew. = 2,827 (Chatard). Dunkelbraun. Glanz perlmutterartig, sich dem halbmetallischen nähernd. - Bläht sich beim Erhitzen ausserordentlich auf. V. d. L. schwierig zu braunem Glase schmelzbar. Beim Erhitzen mit Chlorwasserstoffsäure leicht zersetzbar unter Abscheidung von Kieselsäure in perlmutterglänzenden Schuppen.

Er enthält viele Fragmente von dunkel blaugrauem Korund und mikroskopische, glänzende, anscheinend triklinische Krystálle, welche vielleicht Sphen sind.

Der Name ist nach der Grafschaft Macon in Nord carolina.

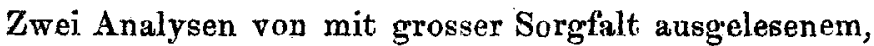
und anscheinend ganz reinem Material wurden von Thomas M. Chatard gemacht; die Alkalien in der zweiten Analyse wurden jedoch von xair bestimmt. 
102 Genth: Ueber Korund, seine Umwandlungen.

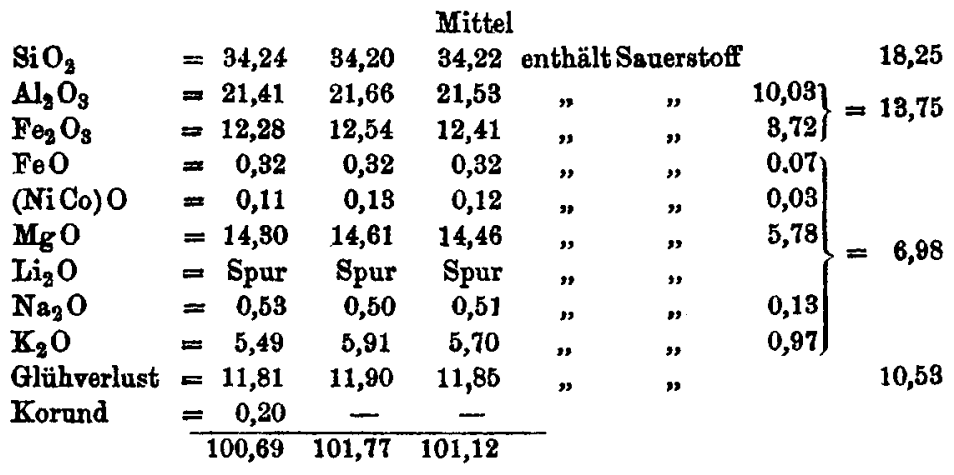

Das Sauerstoffverhältniss der Durchschnitts-Analyse giebt für $\mathrm{RO}: \mathrm{R}_{2} \mathrm{O}_{3}: \mathrm{SiO}_{2}: \mathrm{H}_{2} \mathrm{O}=1,52: 3: 3,98: 2,3$, oder nahezu $3: 6: 8: 5$, in Uebereinstimmung mit der Formel 3RO, $2 \mathrm{SiO}_{2}+2\left(\mathrm{R}_{2} \mathrm{O}_{3}, \mathrm{SiO}_{2}\right)+5 \mathrm{H}_{2} \mathrm{O}$. Etwa $1 / 6$ von $\mathrm{RO}$ sind Alkalien $\mathrm{R}_{2} \mathrm{O}$.

24. Willooxit (ein neues Mineral).

Weisse, grunlich oder graulich-weisse Schuppen von Perlmntterglanz, die dem Talk ähnlich sehen.

V. d. L. in dünnen Splittern schwierig zu weisser Emaille schmelzbar, während die Oxydationsflamme gelb gefärbt wird. Von Chlorwasserstoffsäure beim Erhitzen schwierig zersetzbar mit Abscheidung von Kieselsäure in perlmutterglänzenden Schuppen. Er kommt nur selten vor, und nur zusammen mit Korund als Product seiner Umwandlung. Ein Exemplar von Shooting Creek, Grafschaft Clay, N. C., ist ein Fragment einer halbkugelförmigen Masse, welche vormals wahrscheinlich ganz Korund war, und welche jetzt aus einem Korundkern besteht, umgeben von dem schuppigen Mineral. Der grösste Durchmesser des Stückes ist $2^{1 / 2}$ Zoll, der des Korundkerns $3 / 4$ Zoll.

Name nach Colonel Joseph Willcox, der noch ein grösseres, sonst aber sehr ähnliches Stück besitzt, und der mir viele Hülfe in der Erforschung der Korundmineralien leistete. - 
Weniger rein und mehr mit Korund gemengt findet er sich za Cullakenee, Grafschaft Clay und wahrscheinlich anf der Culsagee-Grube. Dr. Georg A. Koenig machte 2wei Analysen dieses Minerals - 1) von Material den Korundkern umhüllend von Shooting Creek; - 2) von einem Stück ron der Cullakenee-Grube:

\begin{tabular}{|c|c|c|c|c|c|c|c|}
\hline $\mathrm{SiO}_{2}$ & $\begin{array}{c}1 \\
=28,96\end{array}$ & $\begin{array}{c}2 \\
29,50\end{array}$ & $\begin{array}{c}\text { Mitte } \\
\mathbf{2 9 , 2 3}\end{array}$ & athi & uerstoff & & 15,59 \\
\hline $\mathrm{Al}_{2} \mathrm{O}_{3}$ & $=87,49$ & 87,56 & 97,52 & $"$ & " & $17,48)$ & 1788 \\
\hline $\mathrm{Fe}_{2} \mathrm{O}_{3}$ & $=1,26$ & 1,40 & 1,33 & " & $"$ & 0,40 f & \\
\hline $\mathrm{FeO}$ & $=2,44$ & 2,38 & 2,41 & $n$ & $"$ & $0,54)$ & \\
\hline $\mathrm{MgO}$ & $=17,36$ & 17,20 & 17,28 & " & $\eta$ & 6,91 & \\
\hline $\mathrm{Li}_{\mathrm{g}} \mathrm{O}$ & $=\mathbf{S p u r}$ & Spur & Spur & & & - & $=8,53$ \\
\hline $\mathrm{Na}_{2} \mathrm{O}$ & $=6,73$ & 6,24 & 6,48 & " & $"$ & 1,67 & \\
\hline $\mathbf{K}_{2} \mathbf{O}$ & 2,46 & 2,42 & 2,44 & " & $"$ & $0,41)$ & \\
\hline Glühverlust & $=\frac{4,00}{10069}$ & 3,32 & $\frac{3,66}{0035}$ & & & & $\mathbf{8 , 2 0}$ \\
\hline
\end{tabular}

Das Sauerstoffverhältniss von $\mathrm{RO}: \mathrm{R}_{2} \mathrm{O}_{3}: \mathrm{SiO}_{2}: \mathrm{H}_{2} \mathrm{O}$ $=1: 1,88: 1,64: 0,33$ oder ziemlich nahe 6:12:10:2, wolches sich durch die Formel $3\left(2 \mathrm{RO}, \mathrm{SiO}_{2}\right)+2\left(2 \mathrm{R}_{2} \mathrm{O}_{3}, \mathrm{SiO}_{2}\right)$ $+2 \mathrm{H}_{2} \mathrm{O}$ - ausdrücken lässt.

Ohngefähr $1 / 6$ von $\mathrm{RO}$ sind Alkalien $\mathrm{R}_{2} \mathrm{O}$.

\section{Pattersonit.}

Das mit dem Lesleyit von Unionville zusammen vorkommende und von Isaac Lea (l. c.) beschriebene chloritische Mineral Pattersonit, ist von S. P. Sharpless (l.c.) analysirt worden. Seine Analyse ist jedoch so mangelhaft, dass eine neue Untersuchung wünschenswerth erschien, wozu I. L ea eine Quantität vom Original-Material mittheilte.

Spec. Gew. $=2,810$.

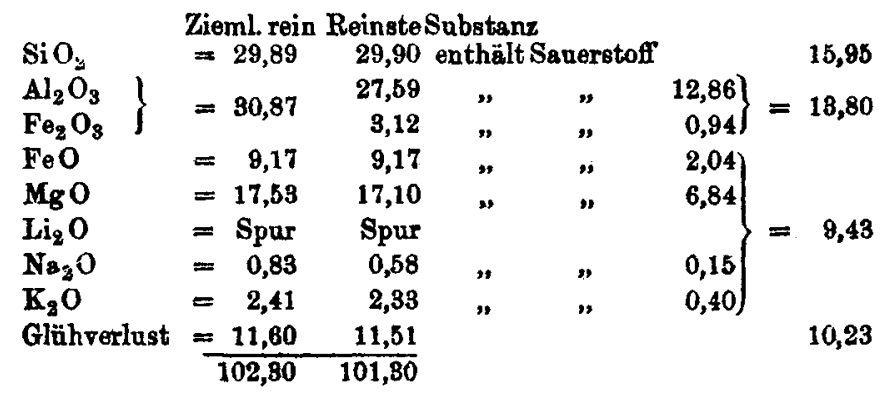


104 Genth: Ueber Korund, seine Umwandlungen,

Das Sauerstoffverhältniss von $\mathrm{RO}: \mathrm{R}_{2} \mathrm{O}_{3}: \mathrm{SiO}_{2}: \mathrm{H}_{2} \mathrm{O}$ ist $=2,05: 3: 3,47: 2,22=6: 9: 10: 6$, entsprechend der Formel : $2\left(3 \mathrm{RO} . \mathrm{SiO}_{2}\right)+3\left(\mathrm{R}_{2} \mathrm{O}_{3} \cdot \mathrm{SiO}_{2}\right)+6 \mathrm{H}_{2} \mathrm{O} .-$ Das Sauerstoffverhältniss ist nahe dem des Thuringits, welches $1: 1,5: 1,5: 1$ ist.

\section{Chloritoid.}

Dieses Mineral ist an vielen Korundlocalitäten beobachtet worden. Zu Kassoibrod am Ural kommt es mit Diaspor, Glimmer und Cyanit vor, in Kleinasien mit Korund, Diaspor und Margarit zu Chester, Mass., mit Korund und Diaspor. - - Ein Stück ans der Grafschaft Augusta in Virginien besteht aus Chloritoid und Damourit und beigemengtem feinzertheiltern Korund; einen kleinen Krystall desselben fand ich in den aus der Ackererde ausgewaschenen Mineralien von Culsagee. Ein sehr interessantes Vorkommen ist das in den Pyrophyllitschiefern aus der Grafschaft Chatham in Nordearolina, in welchen es, manchmal durch die ganze Masse derselben vertheilt, in glänzenden dunkel schwarz-grïnen Krystallschuppen gefiunden wird. Nur mit grosser Sohwierigkeit konnte ich Material, welches anscheinend rein war, in hinreichender Quantität zur Analyse aussuchen.

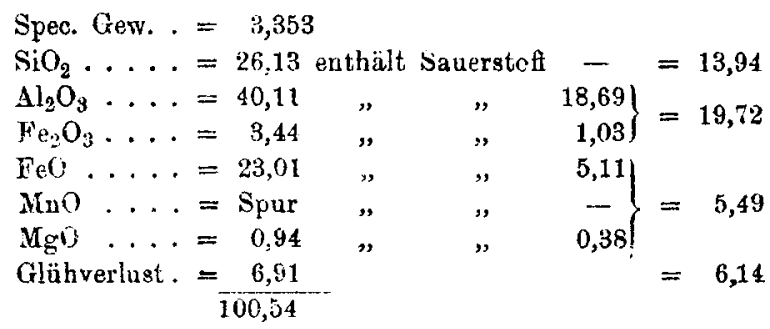

Dus Saueistoffverhältniss von $\mathrm{RO}: \mathrm{R}_{2} \mathrm{O}_{3}: \mathrm{SiO}_{2}: \mathrm{H}_{2} \mathrm{O}$ ist: $0,83: 3: 2,12: 0,87=4: 15: 10: 4$, welches der Formel $4 \mathrm{RO} . \mathrm{SiO}_{2}+5 \mathrm{R}_{2} \mathrm{O}_{3} \cdot 4 \mathrm{SiO}_{2}+4 \mathrm{H}_{2} \mathrm{O}$ entspricht, die besser mit weiner Analyse stimmt, als $4 \mathrm{RO} . \mathrm{SiO}_{2}+4 \mathrm{R}_{2} \mathrm{O}_{3} .3 \mathrm{SiO}_{2}+$ $4 \mathrm{H}_{2} \mathrm{O}$, welche gewithnlich angenommen wird; doch mag 
eine sehr geringe Beimengung von Pyrophyllit diese Differenzen verursachen.

\section{Margarit.}

Dies Mineral war seit langer Zeit von Sterzing in Tyrol bekannt; jedocb erst seit der fast gleichzeitigen Fntdeckung desselben mit Korund von Pennsylvanien und Nordcarolina von Benj. Silliman und mit dem Smirgel in Kloinasien und Griechenland von J. L. Smith wurde seine Wichtigkeit erkannt. Es scheint ein fast niemals fehlender Begleiter des Korunds zu sein und ist aus dessen Zersetzung entstanden. Viele Varietäten desselben sind dera Damourit so ausserordentlich ähnlich, dass beide oft verwechselt wurden. Der einzig sichere Weg der Unterscheidung ist die chemische Analyse.

Zu Unionville, Pa., und zu Crowder's Mln., N. C., finden sich die Korundkrystalle oft mit einem weichen wachsglänzenden Mineral überzogen, mitunter sind die ganzen Krystalle in dasselbe verwandelt. Eine qualitative Analyse zeigte, dass diese Ueberzüge Margarit seien. Besser wurden folgende Varietäten untersucht, von Unionville, $\mathrm{Pa}$.

a) Ein Fragment eines Krystalls, der die Endfläche $O$ und eine Pyramide, welche 2 zu sein scheint, zeigt, besteht aus einem grauweissen weichen Mineral, das mit blossem Auge betrachtet amorph zu sein scheint und obne Glanz ist. Mit einer guten Loupe kann seine krystallinische Structur beobachtet werden, und dass es aus ausserordentlich kleinen perlmutterglänzenden Schüppchen besteht, welche von einem Korundkern, der die Mitte des Krystalls einnimmt, divergiren und dem kryptokrystallinischen Mineral eine etwas pseudofaserige Structur geben. - An der Aussenseite enthält das Mineral kleine Schuppen von Damourit.

Ich habe zwei Analysen des reinsten kryptokrystallinischen Minerals gemacht deren Mittelwerthe ich unten gebe (a 1): zur Bestätigung habe jch eine dritte Analyse angestellt mit Material, welches weniger rein war und 
106 Genth: Ueber Korund, seine Umwandlungen,

einige Schuppen von Damourit enthielt (a 2), deren Einfluss in den etwas höheren Mengen von Kalk sich zeigt.

b) eine weisse blättrige Varietät, die einen schwachen Stich ins Röthliche zeigt, kommt, jedoch nicht häufig, mit Korund auf dem neuerdings entdeckten Korundlager in Begleitung von Turmalin vor. $\mathrm{Er}$ bildet einen Ueberzug oder dünne Schnüre im Korund. Die Blätter sind mitunter beinahe einen Zoll breit, aber gewöhnlich kleiner. Meine Analyse (b).

c) Ein Aggregat feiner Blättchen und Schuppen von einer etwas körnigen Structur und von weisser Farbe mit einem schwachen Stich ins Röthliche, welches in Begleitung von Turmalin vorkommt, schien ein Gemenge von Korund und Margarit zu sein; beim Pulverisiren fand sich aber, dass es fast reiner Margarit war, der nur sehr geringe Quantitäten von Korundkörnern eingeschlossen enthielt. Mit grosser Sorgfalt ausgewähltes Material wurde von Dr. G. A. Koenig untersucht (c).

d) Eine massive, anscheinend dichte oder feinkörnige Varietät ist vor Kurzem mit dem körnigen Korund vorgekommen; unter starker Vergrösserung erscheint sie als ein Aggregat höchst feiner Blättchen, die an einer Seite des Handstücks aus grösseren mit Chlorid gemengten Schuppen bestehen. Farbe weiss, doch sind viele eisenschüssige Punkte durch die Masse vertheilt; das reinste Material wurde von mir analysirt (d).

e) Eine dichte Varietät, welche viele Fragmente von Korund, durch die Masse vertheilt, enthält, wurde von Thomas M. Chatard untersucht (e). Sie hat eine granlich weisse, bis bräunlich weisse Farbe und Wachsglanz. Unter dem Mikroskop zeigte sie eine kryptokrystallinische Structur. Bricht leicht in eckige Fragmente von eins bis zwei Zoll Grösse, die gewöhnlich mit Eisen- und Manganoxydhydrat überzogen sind.

f) Auf der Culsagee Grube findet sich der Margarit nur selten. Ich habe ihn nur in einem stark zu Kaolinit verwitterten feldspathigen Gesteir. in Begleitung einer grünlichen Hornblende und sehr wenigen Chlorids beobach- 
tet. Durcu die ganze Masse sind Körner von weissem und rosenrothem Korund und Blättchen von Margarit vertheilt. Der Margarit ist weiss, blättrig und von Perlmutterglanz. Er wurde von mir (f 1) und Thomas $M$. Chatard (f 2) analysirt.

g) Die schönsten Varietäten von Margarit finden sich auf der Cullakenee-Grube in Nordcarolina. Hier findet er sich in Gruppen blättriger Krystalle, die die prismatischen Flächen deutlich zeigen. Die grösste mir zu Gesicht gekommene Gruppe ist 2 Zoll lang, $11 / 2$ Zoll breit und $5 / 8$ Zoll dick. Die Farbe der basischen Spaltungsflächen ist bräunlich-weiss, nach Behandlung mit verdünnter Chlorwasserstoffsäure, welche einen dünnen Ueberzug von Eisenoxydhydrat entfernt, ist sie schwach röthlichwoiss mit einem Stich ins Silbergrau; die prismatischen Flächen haben eine dunklere Farbe.

Schwarzer Turmalin ist mitunter zwischen den Blättern eingeschlossen, ausserdem findet sich ein bereits oben erwähntes unbekanntes Mineral in dünnen Krystallen eingewachsen. Das wichtigste mit dem Margarit vorkommende Mineral ist Korund, der in Kernen auftritt, die vollständig von dem blättrigen Margarit umgeben sind. Ausserdem kommen Blättchen eines bronze- oder bräunlichgelben Minerals vor, welche wahrscheinlich das Resultat der Zersetzung des Margarits sind und die ich später als Dudleyit beschreiben werde. Thomas M. Chatard untersuchte diese Varietät (g 1$)$.

Eine andere als Zersetzungsproduct von grauweissem, gleichzeitig mit Zoisit auftretende Varietät, ist in breiten, sehr schwach rosenrothen Blättern mit dem Korund gemengt. Meine Analyse (g 2).

Mit dem den Willcoxit begleitenden Korund und ihn einhüllend findet sich eine faserige Varietät, die aus sehr feinen perlmutterglänzenden Blättchen besteht. Dieser Margarit sieht dem Damourit (e) täuschend ähnlich; eine qualitative Analyse zeigte jedoch einen bedeutenden Kalkgehalt und die Abwesenheit von Kali.

Noch eine andere Varietät findet sich in dünnen Schnü- 
108 Genth: Ueber Korudd, seine Umwandlungen,

ren von graulich-grüner Farbe. Bei starker Vergrösserung erscheint sie in feinen Schuppen von grünlich-weisser oder meergrüner Farbe. Meine Analyse (g 3).

h) Krystallinische Massen von grauem Korund aus der Nachbarschaft von Penland's, Grafschaft Olay, Nordearolina, sind mit einem kryptokrystallinischen, pseudofaserigen, weissen oder gelblichweissen Mineral überzogen, das, nach einer qualitativen Untersuchung zu urtheilen, Margarit zu sein seheint.

i) Ich habe bereits oben der eigenthümlichen nierenförmigen und nuregelmässigen Massen von Margarit erwähnt, die bei Gainesville, Grafsehaft Hall in Georgia sich finden und einen Kern von Korund vollstïndig ungeben, ebenso des diese begleitenden erdigen Minerals, das mit Schnüren von grünlich-weissem und ixeergrünem Margarit durchzogen ist. Der Margarit in Berührung mit dem Korund ist manohmal kryptokrystallinisch oder pseudofaserig, aber gewöhnlich aus einem Aggregat von weissen perlmutterglänzenden Blättchen besteheud, von denen ich die Analyse (i 1) machte. Der meergrüne oder grünlichweisse, dem Kalk sehr ähnlich sehende Margarit wurde ebenfalls von mir untersucht (i 2).

k) Eine sehr schöne weisse Varietät von breitblättrigem Margarit findet sich zu Dudleyville, Alahama. Die Blätter sind manchnal $z$ wei Zoll breit und hüllen mitunter blätt. rigen Korund vollständig ein. Eine von mir angestellto Analyse ist unter $(\mathrm{k})$ aufgeführt.

\begin{tabular}{|c|c|c|c|c|}
\hline & (a. 1) & (a. Z) & (b) & (c) \\
\hline Spec. Gew, . = & 3,012 & - & - & - \\
\hline $\mathrm{SiO}_{2} \ldots \ldots=$ & 32,19 & 33,46 & 30,70 & 31,48 \\
\hline $\mathrm{Al}_{2} \mathrm{O}_{3} \ldots=$ & 49,62 & - & 49,33 & 49,01 \\
\hline $\mathrm{FeO} \ldots \ldots=$ & 0,91 & - & 0,39 & 0,52 \\
\hline M. O... & 0,41 & - & 0.76 & 0,54 \\
\hline $\mathrm{CaO} \ldots \ldots=$ & 7,81 & 7,05 & 11,86 & 10,70 \\
\hline $\mathrm{Li}_{2} \mathrm{O} \ldots \ldots=$ & Spur & - & 0,36 & \\
\hline $\mathrm{Na}_{2} \mathrm{O} \ldots=$ & 4,78 & 4,41 & 0,96 & 1,34 \\
\hline $\mathbf{K}_{2} \mathrm{O} \ldots .=$ & 0,57 & 1,02 & 0,65 & \\
\hline Glühverlust . =- & 3,93 & $4,9.4$ & 5,91 & 3,94 \\
\hline \multirow{2}{*}{ Korund $\ldots=$} & - & - & - & 2,00 \\
\hline & 90,22 & & 100,92 & 99,54 \\
\hline
\end{tabular}


und die ihn begleitenden Mineralien.

(d)

Spec. Gew. . $=3,047$

$\mathrm{SiO}_{2} \ldots . .=40,45$

$\mathrm{Al}_{2} \mathrm{O}_{3} \ldots=50,86$

$\mathrm{FeO} \ldots, \ldots=0,42$

$\mathrm{MgO} \ldots \ldots=0,37$

$\mathrm{CaO} \ldots \ldots=12,13$

$\mathrm{Li}_{2} \mathrm{O} \ldots . .=\mathrm{Spur}$

$\mathrm{Na}_{2} \mathrm{O} \ldots=1,72$

$\mathrm{K}_{2} \mathrm{O} \ldots \ldots=0,25$

Glühverhıst. $=4,48$

Korund . . = Spur

$=\frac{\text { spur }}{100,68}$ (e)

3.00

31,29

47,24

0,85

0,88

10,86

Spur

2,66

0,24

5,92 (f 1)

$-$

3,087

(g 1)

$28,11 \quad 28,80 \quad 29,34$

$49,16 \quad 49,57 \quad 48,73$

$\begin{array}{lll}0,43 & 0,34 & 0,78\end{array}$

$0,45 \quad 0,75 \quad 0,78$

$11,08 \quad \mathbf{1 1 , 3 3} \quad \mathbf{1 1 , 3 2}$

0,45 nicht best. Spur

$0,67 \quad$, 2,61

0,22

6,43

, 0,10

$6,64 \quad 6,55$ (g 2)

Spec. Gew. . = 3,055

$\mathrm{SiO}_{2} \ldots \ldots=30, i 2$

$\mathrm{Al}_{2} \mathrm{O}_{3} \ldots==49,83$

$\mathrm{Cr}_{2} \mathrm{O}_{3} \ldots \ldots=-$

$\mathrm{F} 6 \mathrm{O} \ldots . .=0,84$

$\mathrm{MgO} \ldots \ldots=0,76$

$\mathrm{CaO} \ldots . .=10,84$

$\mathrm{Li}_{2} \mathrm{O} \ldots . .=$ Spur

$\mathrm{Na}_{2} \mathrm{O} \ldots=2,19$

$\mathrm{K}_{2} \mathrm{O} \ldots \ldots=0,26$

Glühverlust . $=6,21$

Korund $\begin{array}{rr}-\quad 3,31 \\ 99,94 & 100,31\end{array}$

100,21

(g 3) (i 1) (i 2)

3,064

3,004

3,085

29,63

33,21

32,15

28,71

51,19

48,55

49,28

0,13

0,59

-

0,46

- 57

52,44

1,09

11,28

0,39

0,63

0,39

$-$

30,04

11,09

$0,7.4$

1,22

Spur

Spur

11,52

0,20

1,64

1,18

0,38

4,73

1,39

1,04

0,67

$=\frac{-}{101,65}$

100,06

100,27

100,1

Diese Analysen zeigen, dass in manchen Margariten eine beträchtlige Menge des Kalks durch Alkalien, namentlich durch Natron ersetzt wird. So ist in (a 1 ) etwa der dritte Theil, in (e), ( $g$ 1) und (g 2) etwa ein Sechstel desselben durch Natron substituirt.

Obgleich viele dieser Analysen nur den Zweck der Speciesbestimmung hatten, só stimmen sie doch im Ganzen mit dem bekannten Sauerstoffverhältniss von $R O: \mathrm{R}_{\mathbf{2}} \mathrm{O}_{\mathbf{3}}$ : $\mathrm{SiO}_{2}: \mathrm{H}_{2} \mathrm{O}=1: 6: 4: 1$; einige zeigen etwas grösseren Wassergehalt.

Ich kann nicht unterlassen, hier eine sehr interessante von J. L. Smith (l. c.) gemachte Beobachtung zu erwähnen, und ihr die aus meinen Untersuchungen hervorgehende Erklärung beizufügen. Er sagt: „ein Knollen, 
110 Genth: Ueber Korund, seine Umwandlungen,

der Smirgel im Mittelpunkt enthält, mit zwei concentrischen Schichten, die innere aus Chloritoid, die äussere aus Emerylit (Margarit) bestebend", in anderen Worten, eine Pseudomorphose von Chloritoid und Margarit nach Korund.

28. Erdiges Mineral von Gainesville, Ga.

In Begleitung mit dem grünlichen Margarit dieses Fundorts (i 2), und beide aus Korund entstanden. Structur fein körnig, weich, aber mit einigen härteren Theilchen, die Quarz zu sein scheinen. Farbe zwischen isabell- und fleischfarbig. Enthält eine sehr geringe Beimengung von Margarit.

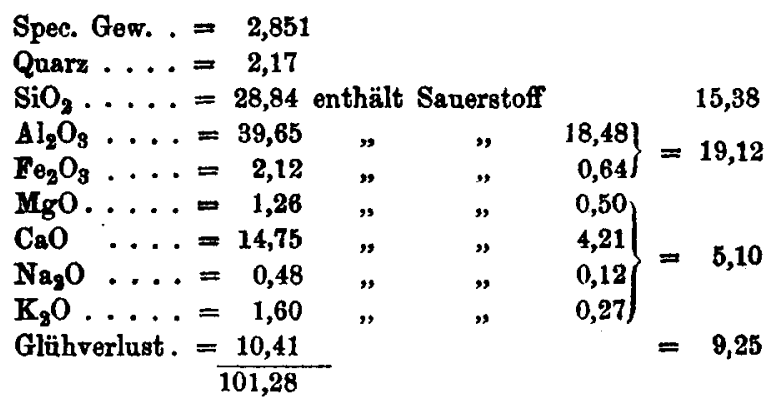

Das Sauerstoffverhältniss von $\mathrm{RO}: \mathrm{R}_{2} \mathrm{O}_{3}: \mathrm{SiO}_{2}: \mathrm{H}_{2} \mathrm{O}=$ $1: 3,75: 3,01: 1,8$ oder nahezu $4: 15: 12: 7$, welches der Formel $2\left(2 \mathrm{RO} . \mathrm{SiO}_{2}\right)+\left(5 \mathrm{R}_{2} \mathrm{O}_{3} .4 \mathrm{SiO}_{2}\right)+7 \mathrm{H}_{2} \mathrm{O}$ entspricht.

Obgleich das Material zur Untersuchung nicht vollständig rein erhalten werden konnte, und ich deshalb dieser Analyse keinen grösseren Werth beilegen möchte, so wünschte ich sie dennoch aus dem Grunde mitzutheilen, weil ich das Mineral für neu halte und hoffe, dass es in reinerem Zustande gefunden werden möge.

20. Dudleyit (ein neues Mineral).

Auf der Culakenee-Grube findet sich sparsam, in grösserer Quantität dagegen zu Dudleyville, Ala., ein weiches, bronze- oder braungelbes Mineral, welches das Resultat der Zersetzung des Margarits zu sein scheint, und 
dessen Form noch beibehält. Es besitzt schwachen Perlmutterglanz. Vor dem Licht bläht es sich nur wenig auf urd schmilzt mit Schwierigkeit zu einer braungelben blasigen Masse. Von Chlorwasserstoffsäure wird er leicht unter Abscheidung von Kieselsäure in perlglänzenden Sehuppen zersetzt.

Name nach dem Fundorte Dudleyville, Ala. Die Analyse gab:

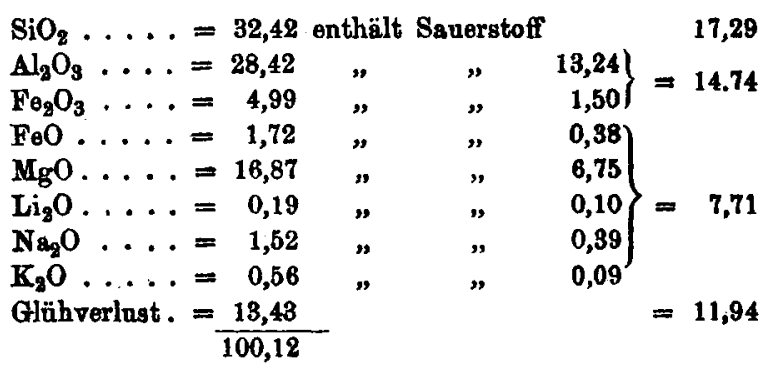

Das Sauerstoffverhältniss von $\mathrm{RO}: \mathrm{R}_{2} \mathrm{O}_{3}: \mathrm{SiO}_{2}: \mathrm{H}_{2} \mathrm{O}=$ $1: 1,91: 2,24: 1,55$ ist ziemlich nahe $=6: 12: 14: 10$, woraus sich die Formel : $2\left(3 \mathrm{RO} .2 \mathrm{SiO}_{2}\right)+\left(4 \mathrm{R}_{2} \mathrm{O}_{3} .3 \mathrm{SiO}_{2}\right)+10 \mathrm{H}_{2} \mathrm{O}$, entwickeln lässt.

30. Lazulit.

Als ich die Umwandlung des Korunds von Crowder's and Clubb's Mountain's, Grafschaft Gaston, Nordcarolina, erwähnte, bemerkte ich, dass Lazulit dort und an allen analogen Fundorten als eines der Umwandlungsproducte auftritt.

Der Lazulit findet sich entweder in Krystallen oder derben Massen mit sandigem Quarz, oder mit Damourit und Cyanit; sehr interessant sind die im Lazulit eingeschlossenen Rutilkrystalle, da sie an den erwähnten Localitäten der beständige Begleiter des unveränderten Korunds sind, also den Ursprung des Lazulits beweisen.

Obgleich nicht in Uebereinstimmung mit den Ansichten der neueren Chemie, hielt ich es dennoch für zweckmässig, die erhaltenen analytischen Resultate durch For- 
112 Gonth: Ueber Korund, seine Unwandlungen etc.

meln auszudrücken. Ich lege denselben keinen grösseren Werth bei, als sie verdienen. Sie haben jedenfalls den Vortheil, vielen Mineralogen und Geologen, die sich an solche Ausdrücke gewöhnt haben, ein Bild von der Zusammensetzung derselben vor Augen zu führen, was unstreitig mehr ist, als eine empirisehe Formel thun kann.

Die durch vorstehende Untersuchung gewonnenen Thatsachen lassen sich kurz in folgende Sätze zusammenfassen:

1. Während der grossen Periode in der die chromhaltigen Chrysolitlager (an vielen Orten zu Serpentin umgewandelt) gebildet wurden, ward eine grosse Quantität Thonerde ausgeschieden, welche mächtige Korundlager bildete;

2. Dieser Korund wurde später mehr oder weniger verändert, und in verschiedene Mineralien umgewandelt, wie in Spinell, Fibrolit, Cyanit, wabrscheinlich in einige Feldspathvarietäten, sowie in Turmalin, Damourit, Chlorit, Margarit;

3. Die Producte dieser Umwandlungen bestehen theilweise noch in grossen Lagern von Glimmer (Damourit) und Chloritschiefern;

4. theilweise sind sie in andere Mineralien und Felsarten weiter umgewandelt worden, und bildeten Pyrophyllit, Paragonit, Beauxit, Lazulit u. s. w.

Die Frage, wie ein so unlöslicher Körper, wie Korund, solche grossartige Zersetzungen erlitten haben könne, lasse ich unerörtert. Ich habe in der ganzen Untersuchung nur Thatsachen mitgetheilt, und muss die Frage über ihre Entotehung der Zukunft anheimstellen.

Universität von Pennsylvanien.

Philadelphia, am 4. Januar 1874. 